\title{
Study and design of the ion cyclotron resonance heating system for the stellarator Wendelstein 7-X
}

\author{
J. Ongena, ${ }^{1}$ A. Messiaen, ${ }^{1}$ D. Van Eester, ${ }^{1}$ B. Schweer, ${ }^{1}$ P. Dumortier, ${ }^{1}$ F. Durodie, ${ }^{1}$ \\ Ye. O. Kazakov, ${ }^{1}$ F. Louche, ${ }^{1}$ M. Vervier, ${ }^{1}$ R. Koch, ${ }^{1}$ A. Krivska, ${ }^{1}$ A. Lyssoivan, ${ }^{1}$ \\ M. Van Schoor, ${ }^{1}$ T. Wauters, ${ }^{1}$ V. Borsuk, ${ }^{2}$ O. Neubauer, ${ }^{2}$ O. Schmitz, ${ }^{2}$ G. Offermans, ${ }^{3}$ \\ Y. Altenburg, ${ }^{4}$ C. Baylard, ${ }^{4}$ D. Birus, ${ }^{4}$ S. Bozhenkov, ${ }^{4}$ D. A. Hartmann, ${ }^{4}$ J. P. Kallmeyer, ${ }^{4}$ \\ S. Renard, ${ }^{4}$ R. C. Wolf, ${ }^{4}$ and T. Fülöp ${ }^{5}$ \\ ${ }^{1}$ Laboratory for Plasmaphysics, Ecole Royale Militaire-Koninklijke Militaire School, TEC Partner, \\ Brussels, Belgium \\ ${ }^{2}$ IEK-4/Plasmaphysik, Forschungszentrum Juelich, TEC Partner, Juelich, Germany \\ ${ }^{3}$ ZEA-1, Forschungszentrum Juelich, Juelich, Germany \\ ${ }^{4}$ Max-Planck Institute für Plasmaphysik, Teilinstitut Greifswald, Greifswald, Germany \\ ${ }^{5}$ Nuclear Engineering, Chalmers University of Technology, Göteborg, Sweden
}

(Received 20 November 2013; accepted 5 February 2014; published online 26 June 2014)

The current status of the mechanical and electromagnetic design for the ICRF antenna system for W7-X is presented. Two antenna plugins are discussed: one consisting of a pair of straps with prematching to cover the first frequency band, 25-38 MHz, and a second one consisting of two short strap triplets to cover a frequency band around $76 \mathrm{MHz}$. This paper focusses on the two strap antenna for the lower frequency band. Power coupling of the antenna to a reference plasma profile is studied with the help of the codes TOPICA and Microwave Studio that deliver the scattering matrix needed for the optimization of the geometric parameters of the straps and antenna box. Radiation power spectra for different phasings of the two straps are obtained using the code ANTITER II and different heating scenario are discussed. The potential for heating, fast particle generation, and current drive is discussed. The problem of RF coupling through the plasma edge and of edge power deposition is summarized. Important elements of the complete ion cyclotron resonance heating system are discussed: a resonator circuit with tap feed to limit the maximum voltage in the system, and a decoupler to counterbalance the large mutual coupling between the 2 straps. The mechanical design highlights the challenges encountered with this antenna: adaptation to a large variety of plasma configurations, the limited space within the port to accommodate the necessary matching components and the watercooling needed for long pulse operation. [http://dx.doi.org/10.1063/1.4884377]

\section{INTRODUCTION}

The Wendelstein 7-X (W7-X) stellarator (average minor and major radius $\mathrm{a}=0.55 \mathrm{~m}$ and $\mathrm{R}_{0}=5.5 \mathrm{~m}$, average magnetic field on axis $2.5 \mathrm{~T}$ ) with superconducting coils, under construction in Greifswald, will be the first "fullyoptimized" stellarator. ${ }^{1}$ It will be the largest device of this class in the world. The mission of the project is to demonstrate the reactor potential of the optimized stellarator line. ${ }^{2}$ To demonstrate that reactor relevant plasma parameters can be achieved in steady-state, the $\mathrm{W} 7-\mathrm{X}$ experiment is designed for plasma pulses with 30 min duration at a heating power of $10 \mathrm{MW}$, with Electron Cyclotron Resonance Heating $(\mathrm{ECRH})$ at $140 \mathrm{GHz}$ as main heating system. This is complemented by Neutral Beam Injection (NBI) and Ion Cyclotron Resonance Heating (ICRH) for shorter pulse durations (up to $10 \mathrm{~s}$ ). One of the main aims of W7-X is to demonstrate good fast ion confinement at fusion-relevant $\beta$ values of about $4 \%$. To mimic the behaviour of alpha particles in a future stellarator reactor, a source of sufficiently energetic ions with energies in the range of $50-100 \mathrm{keV}$ is needed in W7-X. Installation of an ICRH system is foreseen to ensure the creation of such populations.
This paper presents main features of the ICRH system that is currently under design for W7-X. Aiming at a power of $\sim 1 \mathrm{MW}$ such a system provides a heating and current drive tool complementing the steady-state ECRH for short periods. Since-unlike tokamaks-stellarators do not suffer from a density limit, core densities between 2 and $4 \times 10^{20} \mathrm{~m}^{-3}$ are foreseen for routine operation. ICRH will provide central plasma heating in such plasmas. At lower densities-closer to those of tokamaks-ICRH can create high energy tails. It also has potential for electron current drive aiming at assisting the study of fast particle confinement. Finally, the system can also provide Ion Cyclotron Wall Conditioning (ICWC). Specific parameter settings will be needed to maximize the effect of each of the four applications of the system. The specific advantage of ICRH is the absence of a cut-off at high density, allowing applications beyond the capabilities of standard ECRH in the magnetic topology of a stellarator.

The ICRH antenna is intended to mostly operate in conjunction with the ECRH system, thus at a main magnetic field of $2.5 \mathrm{~T}$ for which there is second harmonic absorption of X-Mode at $140 \mathrm{GHz}$.

Initially, a feasibility study was conducted to design an antenna for operating over the whole frequency range of 
equatorial cut

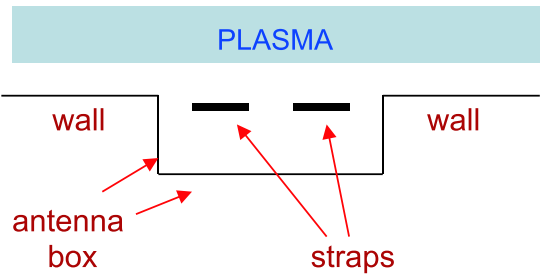

(a)

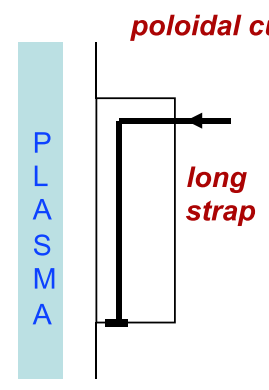

(b)

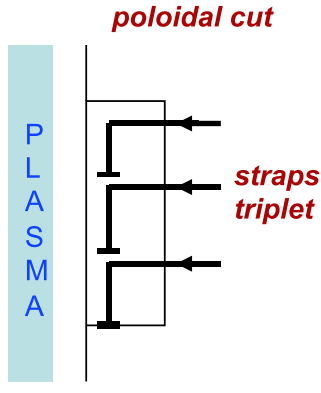

(b)
FIG. 1. (a) Equatorial cut of the antenna system showing the position of the straps with respect to the antenna box and the plasma. (b) Poloidal cut of the antenna plug-in for the frequency band 25-38 MHz with two long straps positioned next to each other in the antenna box. (c) Poloidal cut of the antenna plug-in for the frequency band around $76 \mathrm{MHz}$. with two sets of three short straps positioned next to each other.
25-76 MHz to cover a large range of ICRF scenarios. It was found that with the capacitors available for installation in the limited space of the port such prematching cannot be achieved over the whole frequency range.

Therefore, two antenna plug-ins are proposed:

- a first antenna plug-in to cover the frequency band $25-38 \mathrm{MHz}$ for $\mathrm{H}$ or ${ }^{3} \mathrm{He}$ minority heating at $\omega=\omega_{\mathrm{ci}}$ and

- a second one for operation in a frequency band with $76 \mathrm{MHz}$ as main frequency for $\omega=2 \omega_{\mathrm{cH}}$ minority heating.

These antennas are proposed to be interchangeable, i.e., the outside connections will remain the same, and only the parts internal to the port will need to be exchanged, as will be discussed below. The matching components, however, will have to be adapted to the new frequency band, but are outside the torus hall. For the first frequency band the TEXTOR generators and RF hardware can be used. The second one can be implemented depending upon the availability of the necessary generator(s) at $76 \mathrm{MHz}$. The selected antenna configurations to meet the foreseen applications and the narrow space available in the port at W7-X are: (i) a pair of long straps for the $25-38 \mathrm{MHz}$ band and (ii) a pair of triplets of short straps for the $76 \mathrm{MHz}$ band (see Figs. 1(a)-1(c)). These antenna systems will be analysed in Secs. III-V after a discussion on the choice and potential of different ICRH scenarios.

The structure of the present paper is as follows: in Sec. II, the various possible ICRH scenarios are discussed, with a focus on coupling and wave absorption aspects. In Sec. III follows an outline of the electromagnetic design, and in Sec. IV the mechanical design is summarized. Finally, a list of diagnostics for safe operation of the antenna and to monitor its performance is provided in Sec. V.

\section{ICRH SCENARIOS FOR W7-X AND POTENTIAL FOR HEATING, CURRENT DRIVE AND FAST PARTICLE GENERATION}

One of the key questions that need to be addressed is whether in a future stellarator reactor confinement of the high energy fusion alphas is sufficiently good to ensure sufficient self heating of the plasma. At the standard magnetic field of $2.5 \mathrm{~T}$ in $\mathrm{W} 7-\mathrm{X}, \mathrm{H}$ fundamental cyclotron heating, and second harmonic $\mathrm{D}$ or ${ }^{4} \mathrm{He}$ heating is possible at the high end $(38 \mathrm{MHz})$ of the first frequency range of $25-38 \mathrm{MHz}$; the low end $(25 \mathrm{MHz})$ of this frequency range ensures efficient fundamental cyclotron ${ }^{3} \mathrm{He}$ heating. The ion cyclotron layer positions versus magnetic field for both limiting frequencies are shown in Fig. 2.

The RF scenario for the second frequency band $(76 \mathrm{MHz})$ at $2.5 \mathrm{~T}$ is the $2 \mathrm{nd}$ harmonic $\mathrm{H}$ heating scenario in ${ }^{4} \mathrm{He}$ or D. At a toroidal field of $1.25 \mathrm{~T}$, the following scenarios are applicable: 2nd harmonic ${ }^{3} \mathrm{He}$ in $\mathrm{H}, \mathrm{D}$ or ${ }^{4} \mathrm{He}$ $(25 \mathrm{MHz})$, 2nd harmonic $\mathrm{H}$ heating in ${ }^{4} \mathrm{He}$ or $\mathrm{D}(38 \mathrm{MHz})$ and possibly also 3 rd harmonic ${ }^{3} \mathrm{He}$ heating in ${ }^{4} \mathrm{He}$ or $\mathrm{D}$ (38 MHz).

The RF power deposition in the plasma bulk depends on (i) the RF power coupling from the antenna to the plasma bulk through the plasma edge and (ii) the absorption in the plasma bulk by the plasma species for the heating scenario(s) considered. These two aspects will be discussed briefly in what follows.
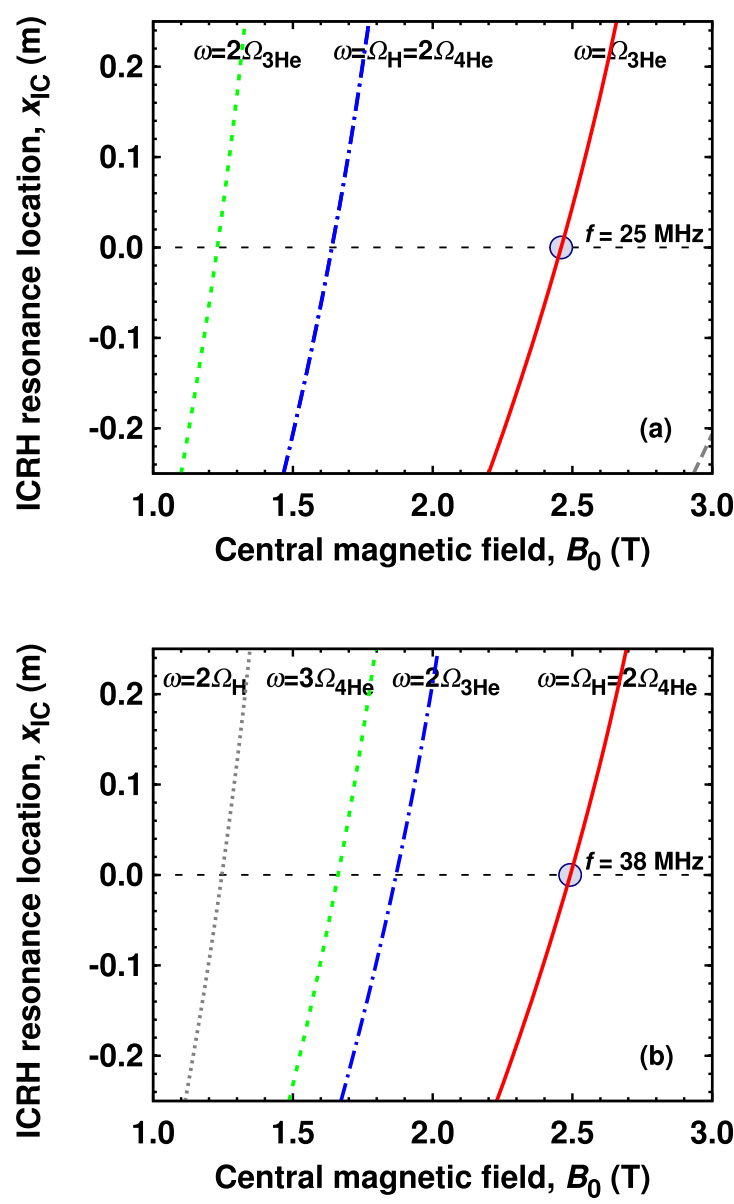

FIG. 2. Ion cyclotron resonance locations at 25 and $38 \mathrm{MHz}$. 


\section{A. Coupling of the RF waves through the plasma edge}

The problem of coupling through the plasma edge and radiated power spectrum has been analysed, to a first approximation, ${ }^{3}$ by means of the analytical coupling code ANTITER II ${ }^{4}$ for the different relative phasings of the two straps considered for the antenna system discussed in this paper: $(00),(0 \pm \pi / 2),(0 \pi)$. This code uses a Fourier analysis in $\left(\mathrm{k}_{\mathrm{z}}, \mathrm{k}_{\mathrm{y}}\right)$ space ( $\mathrm{z}$-axis along the toroidal field $\mathrm{B}$, therefore $\mathrm{k}_{\mathrm{z}} \equiv \mathrm{k}_{/ /}, \mathrm{y}$-axis perpendicular to the $\mathrm{z}$-axis and radial axis) assuming a simplified antenna geometry (recessed antenna box in the device wall with 2 thin straps ${ }^{3}$ ), which is close to the intended final antenna geometry. This code describes coupling of the fast wave to an inhomogeneous cold plasma. The antenna $\mathrm{k}_{/ /}$(or equivalently $\mathrm{k}_{\mathrm{z}}$ ) power spectrum launched at the antenna, as obtained with ANTITER II, is given in Fig. 3 using the reference density profile provided by the W7-X team (Fig. 4). The $\left|\mathrm{k}_{/ /}\right|$values at the peak of the radiated power correspond to $\sim 11 \mathrm{~m}^{-1}$ for $(0 \pi), \sim 6.5 \mathrm{~m}^{-1}$ for $(0 \pm \pi / 2)$, and $<\sim 2.5 \mathrm{~m}^{-1}$ for $(00)$ phasing.

Coupling of RF power by an ICRH antenna to a highdensity plasma region through an inhomogeneous edge plasma density depends mainly on the distance between the antenna and the cutoff density for the waves and on the density gradient from the cutoff to the bulk density. ${ }^{5}$ The cutoff density for the fast wave increases with $\left|\mathrm{k}_{/ /}\right|$for a given ion mix, frequency, and magnetic field under the condition that $\left|\mathrm{k}_{/ /}\right|$is larger than the vacuum wave propagation constant $\mathrm{k}_{0}=\omega / \mathrm{c}$ (with $\mathrm{c}$ is the speed of light in vacuum). Therefore, the wave has to tunnel through a larger distance for antenna phasings corresponding to higher $\left|\mathrm{k}_{/ /}\right|$values. This explains that the highest coupling occurs for monopole phasing $\left(\begin{array}{ll}0 & 0\end{array}\right)$ but this phasing also leads to significant excitation of coaxial and surface modes for parallel wave numbers $\left|\mathrm{k}_{/ /}\right|<\mathrm{k}_{0}$ with power absorption into the plasma edge. Dipole $(0 \pi)$ phasing excludes the low $\mathrm{k}_{/ /}$region and is the best phasing for

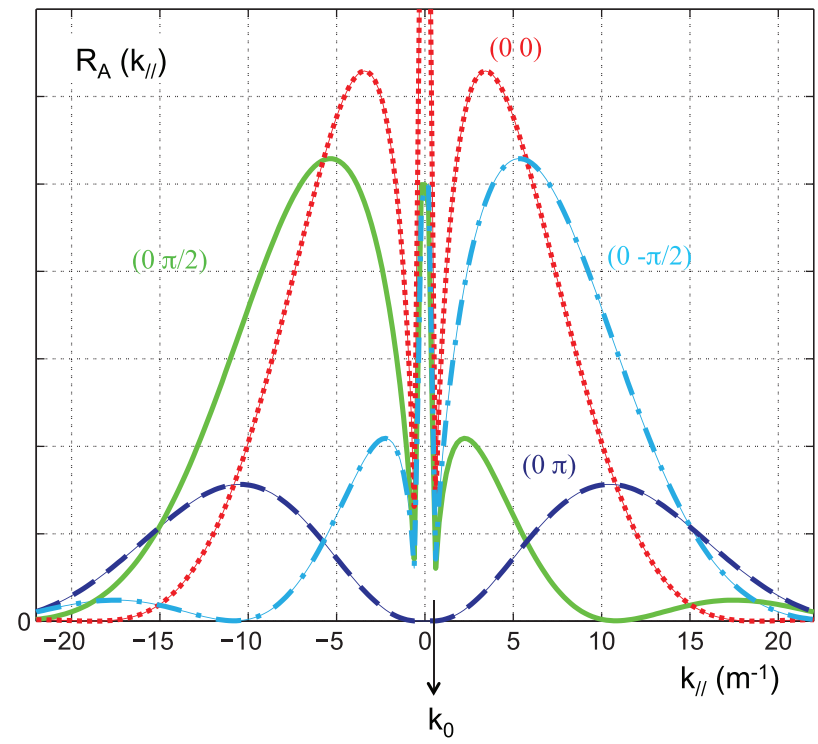

FIG. 3. Antenna $\mathrm{k}_{/ /}$power spectrum as calculated by ANTITER II. The dotted curve corresponds to $\left(\begin{array}{ll}0 & 0\end{array}\right)$ phasing for ICWC applications, full and dotted-dashed curves to $(0 \pm \pi / 2)$ phasing for current drive applications, and the dashed curve to $(0 \pi)$ ) phasing for plasma heating.

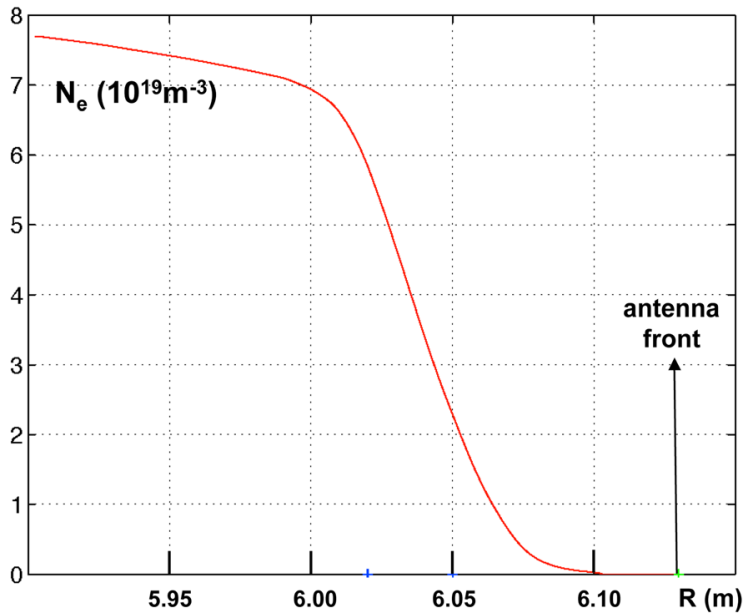

FIG. 4. Reference density profile used for the coupling calculations in this paper, as provided by the W7-X team.

heating. It has however the worst coupling performance because the maximum excitation is at higher $\mathrm{k}_{/ /}$values $\left(\sim 11 \mathrm{~m}^{-1}\right)$. An intermediate coupling performance is obtained for the $(0 \pm \pi / 2)$ phasing with current drive effect, due to its maximum excitation at $\mid \mathrm{k}_{/} / \sim 6.5 \mathrm{~m}^{-1}$ (see Fig. 3) but with some excitation of the coaxial modes. This phasing could also be used for heating at a larger power level due to its best coupling performances.

When the Alfvén resonance or an ion-ion hybrid resonance (IIHR) is present in the edge, part of the RF power is deposited in this region because of the confluence between the fast wave and a kinetic mode that is absent in the cold plasma approximation. This effect is compared for two heating scenarios at $\mathrm{B}_{\text {edge }}=2.27 \mathrm{~T}$ (corresponding to a central $\mathrm{B}_{0}=2.5 \mathrm{~T}$ ) in Figs. 5(a)-5(d): (i) the usual $\mathrm{H}$ minority heating scenario in a D (or ${ }^{4} \mathrm{He}$ ) majority plasma and (ii) the so-called inverted scenario with $\mathrm{D}$ minority in a $\mathrm{H}$ majority plasma. The location of the wave cutoff and resonances in a frequency-electron density diagram is shown for the two cases, respectively, in Figs. 5(a) and 5(b) for the typical $k_{/ /}$ and $\mathrm{k}_{\mathrm{y}}$ values corresponding to the maximum excitation by the $(0 \pi)$ phasing. The figures show the contours of the corresponding radial propagation constant $\mathrm{k}_{\mathrm{x}}$. Note that $\mid \mathrm{k}_{/} / \mathrm{l}>\mathrm{k}_{0}$ in the considered frequency range (as $\mathrm{k}_{0}=2 \pi \mathrm{f} / \mathrm{c}$ remains smaller than $\mathrm{k}_{/ /} \sim 10 \mathrm{~m}^{-1}$ up to $\mathrm{f}=477 \mathrm{MHz}$ ) and in this case the Alfvén resonance is present at a frequency lower than the cyclotron frequency of the majority. For the $\mathrm{D}(\mathrm{H})$ case, an edge Alfvén resonance is present for $\mathrm{f}<\mathrm{f}_{\mathrm{CD}}=17.3 \mathrm{MHz}$ (outside the considered frequency band) and a IIHR between $\mathrm{H}$ and $\mathrm{D}$ just below $\mathrm{f}=\mathrm{f}_{\mathrm{cH}}=34.6 \mathrm{MHz}$. For the $\mathrm{H}(\mathrm{D})$ case, the edge Alfvén resonance is present for $\mathrm{f}<\mathrm{f}_{\mathrm{cH}}=34.6 \mathrm{MHz}$, i.e., partly in the considered frequency range and the IIHR between $\mathrm{H}$ and $\mathrm{D}$ is present around $\mathrm{f}=\mathrm{f}_{\mathrm{CD}}=17.3 \mathrm{MHz}$.

A computation of the resulting distributed antenna radiation resistance by ANTITER for both cases and the different strap phasings is shown in Figs. 5(c) and 5(d) as a function of the frequency in the band $25-38 \mathrm{MHz}$ for the reference plasma profile. For both cases, the coupling is the largest for the $(00)$ phasing and the lowest for the $(0 \pi)$ one as expected. The large effect of the IIHR between D and H 


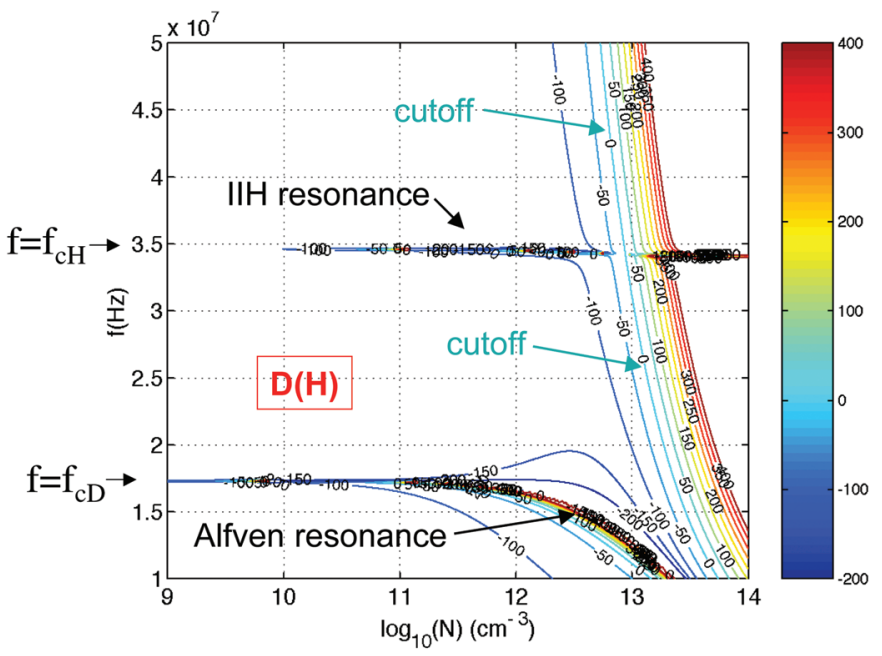

(a)

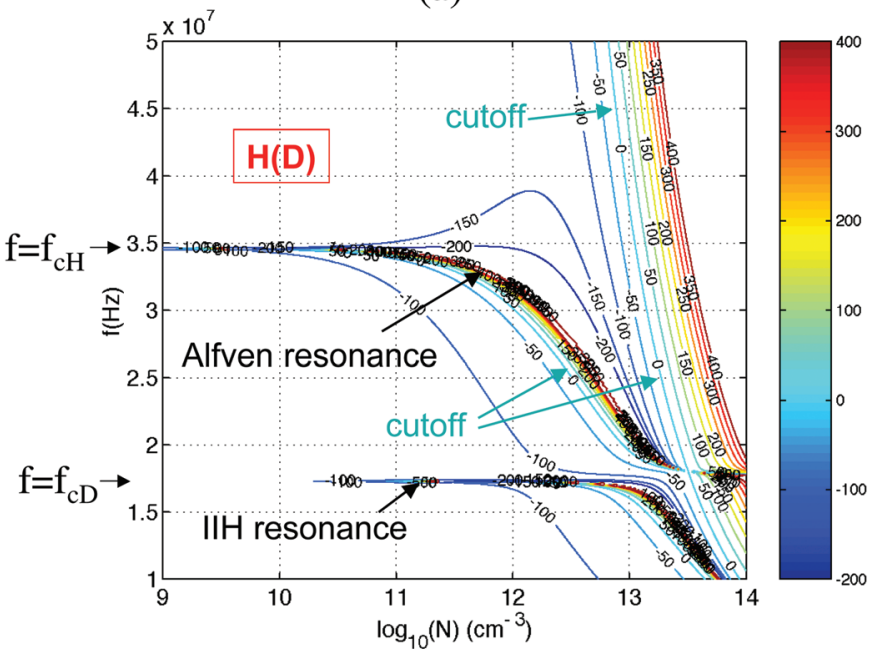

(b)

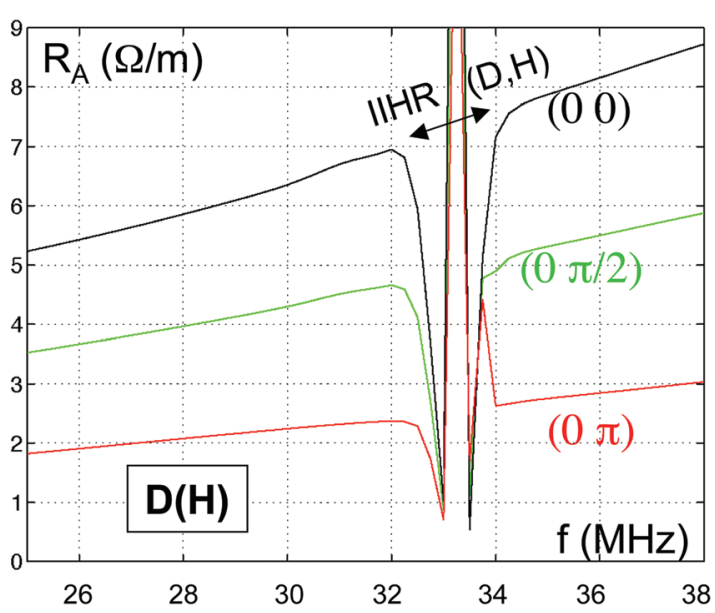

(c)

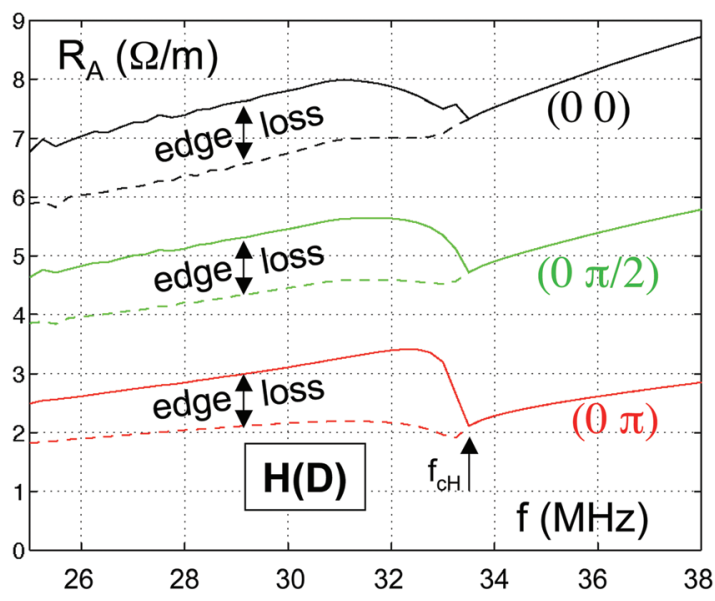

(d)

FIG. 5. (a) Location of the cut-off and resonances in a frequency-density diagram for the $\mathrm{D}(\mathrm{H})$ heating scenario. (b) Location of the cut-off and resonances in a frequency-density diagram for the $H(D)$ heating scenario. (c) Distributed mean radiation resistance $R_{A}(\Omega / m)$ versus frequency for the $D(H)$ heating scenario for three different relative phasings of the two straps of the antenna. (d) Distributed mean radiation resistance $R_{A}(\Omega / m)$ versus frequency for the H(D) heating scenario for three different relative phasings of the two straps of the antenna. In contrast to the $\mathrm{D}(\mathrm{H})$ scenario, a large difference is found for frequencies lower than the ion cyclotron frequency of the majority gas. Full lines indicate the total absorption in the plasma in the absence of the edge Alfven resonance, dashed lines indicate the power reaching the bulk plasma after passing the Alfven resonance.

on the coupling is seen for the $\mathrm{D}(\mathrm{H})$ case in Fig. 5(c). The edge power loss due to the occurrence of an edge Alfvén resonance for $\mathrm{f}<\mathrm{f}_{\mathrm{cH}}$ in the $\mathrm{H}(\mathrm{D})$ case is shown in Fig. 5(d). Full lines correspond to the total radiated power by the antenna and the dashed lines correspond to the power reaching the plasma bulk after passing through the Alfvén resonance. The amount of power absorbed at this resonance for $\mathrm{a}\left(\mathrm{k}_{/}, \mathrm{k}_{\mathrm{y}}\right)$ Fourier component is given by the jump $\Delta \mathrm{P}$ of the real part of the Poynting vector at the resonance. This jump $\Delta \mathrm{P}=\left(\pi \omega \varepsilon_{o} \varepsilon_{2} / 2\left|\varepsilon_{1}^{\prime}\right|\right)\left(\left|\mathrm{E}_{\mathrm{y}}-\mathrm{ik}_{\mathrm{y}} \omega \mathrm{B}_{\mathrm{z}} /\left(k_{0}^{2} \varepsilon_{2}\right)\right|^{2}\right.$, where $\mathrm{i} \varepsilon_{o} \varepsilon_{2}$ is the $\mathrm{xy}$ term of the plasma tensor and $\varepsilon_{o} \varepsilon_{1}^{\prime}$ is the radial derivative of the $\mathrm{xx}$ term at the resonance. Fig. 6 illustrates this jump for the Fourier component $\left(\mathrm{k}_{/ /}=10 \mathrm{~m}^{-1}, \mathrm{k}_{\mathrm{y}}=1 \mathrm{~m}^{-1}\right)$ occurring at the location of the resonance corresponding to the different frequencies. The Poynting vector versus the radial coordinate $\mathrm{x}$ is shown normalized to its value at the exit of the antenna box (located at $\mathrm{x}=0.23 \mathrm{~m}$ in this figure). The edge loss shown in Fig. 5(d) corresponds to the effect of

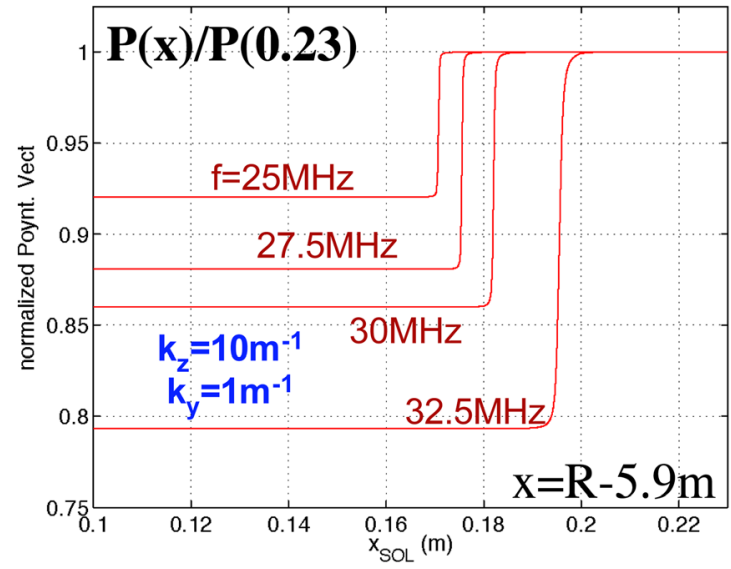

FIG. 6. Value of the Poynting vector normalized to its value at the exit of the antenna box (located at $\mathrm{x}=0.23$ in this figure) versus the radial coordinate $\mathrm{x}$, for different frequencies. $\mathrm{k}_{/ /}=10 \mathrm{~m}^{-1}$ is assumed in this figure, corresponding to $(0, \pi)$ phasing. Up to $\sim 35 \%$ of the total power radiated by the antenna can be deposited in the plasma edge. 
$\Delta \mathrm{P}\left(\mathrm{k}_{/ /}, \mathrm{k}_{\mathrm{y}}\right)$ on the complete Fourier spectrum. The figure shows that a significant fraction of the radiated power (up to $35 \%$ in this example) can be deposited in the plasma edge. Similar plots can be drawn for the $\mathrm{H}-\left({ }^{3} \mathrm{He}\right)$ inverted scenario.

\section{B. Absorption of the RF waves in the bulk plasma}

First estimates for the single transit absorption of these schemes have been obtained with the 1D code TOMCAT$\mathrm{U}^{6}$ usually taking only one toroidal mode launched in the plasma, corresponding to the dominant peak in the $\mathrm{k}_{/ /}$spectrum. As models are not yet available to properly account for the stellarator geometry, the wave equation was solved in equivalent tokamak geometry by adapting the minor and major radii to approximately match the actual variation of the magnetic field in front of the W7-X ICRH antenna and considering adequate profiles for density and temperature. Fig. 7(b) shows the radial dependence of the magnetic field in 2 horizontal planes, and the fitting used to simulate this behaviour. They are deduced from the configuration of the

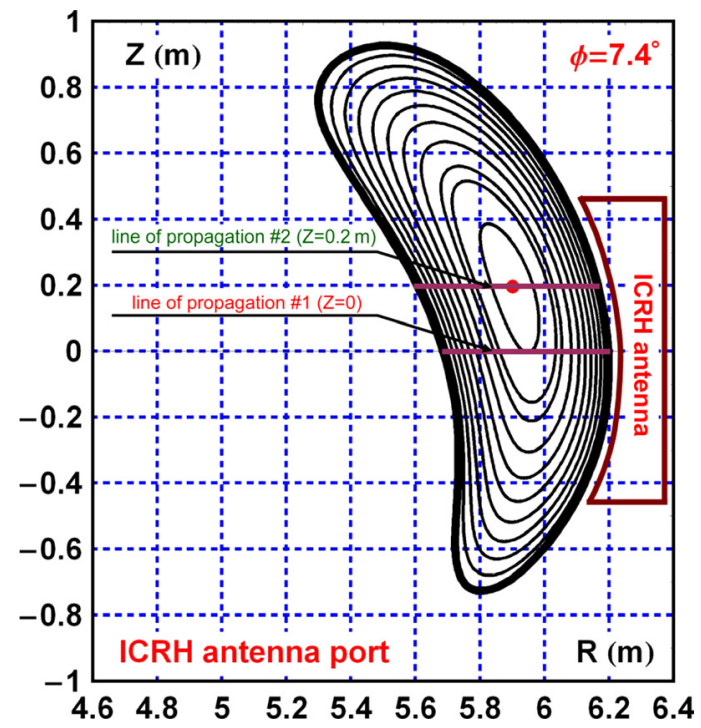

(a)

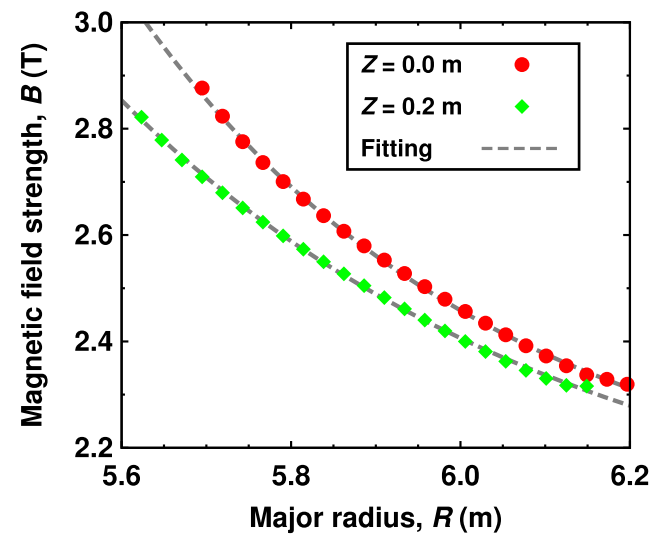

(b)

FIG. 7. (a) Magnetic surface configuration in front of the antenna. (b) Radial dependence of the magnetic field strength and corresponding fits (dashed lines) in the equatorial plane $(\mathrm{z}=0.0 \mathrm{~m})$ and in a horizontal plane $20 \mathrm{~cm}$ above the equatorial plane $(\mathrm{z}=0.2 \mathrm{~m})$. magnetic surfaces in front of the antenna (Fig. 7(a)). The equivalent minor and major radii used in calculations for this paper are $\sim 0.275 \mathrm{~m}$ and $2.4 \mathrm{~m}$, respectively.

In a Faraday cage-such as the metallic plasma vessel-all electromagnetic power launched from an antenna must ultimately be absorbed. In the plasma bulk, the absorption mechanism is collisionless damping, a process well captured by linear wave theory for ICRH waves. In the plasma edge, however, absorption is due to nonlinear interactions between the particles and the waves (cfr. sheaths) and weakcollisional damping. To date, wave absorption in the plasma edge is poorly quantified in deposition codes. The wave generally sloshes over the plasma bulk and plasma edge region a number of times before it is damped. Provided the relative phase of wave fronts is not important, the relation between single pass and multiple pass is straightforward: if a fraction $\eta$ of the power is absorbed in the first full transit (i.e., the wave travels once back and forth), a fraction (1- $\eta$ ) re-enters the plasma so that $\eta(1-\eta))$ is absorbed in the second bounce, $\eta(1-\eta)^{2}$ in the third, etc. Summing over an infinite number of crossings yields - as expected — complete absorption. As $\eta$ is composed of a core and an edge damping part, the same reasoning yields a heating efficiency $\eta_{\mathrm{c}}$ and $\eta_{\mathrm{e}}$ for the core and edge, respectively. Hence the single pass absorption-adopted in this paper to characterize the heating efficiency - is a direct measure for the relative importance of the core to the edge heating, while information on the heating in the core region is lost when including the vessel walls. What we quote in the paper as heating efficiencies are values for $\eta_{\mathrm{c}}$.

The calculation of heating efficiency adapted here only intends to quantify the efficiency with which a wave is absorbed over a single full transit in the plasma bulk. For this reason, the edge plasma in front of the antenna is purposely not included in TOMCAT. TOMCAT assumes pure fast wave incidence from the antenna and evaluates not only the absorption but also the connection coefficients (reflection, transmission and mode conversion) to the various outgoing modes at the plasma boundary. To this end, a 12th order differential equation accounting for Landau and TTMP damping is solved in TOMCAT, taking into account up to 3rd cyclotron harmonic heating. In this way, we not only obtain an idea of the relative importance of the absorption by various mechanisms but also of the overall absorption efficiency in the plasma bulk. This differs from the commonly used approach where the linear wave equations are integrated in the full vessel, including the metallic walls, leading to the impression that all power is ultimately absorbed in the plasma bulk. Complemented with a proper edge damping model, the total absorption can then be assessed. Since the edge damping is typically weak, it is of limited importance for high single pass absorption schemes. In heating schemes with poor bulk heating, the edge heating mechanisms can, however, be of significance. Since the bulk heating can be steered by properly tuning the heating scheme while the edge heating is poorly understood and thus poorly controlled, optimizing a heating scheme is done in practice by choosing apt parameters for maximizing the bulk heating. 
Because of the high densities achievable in a stellarator, the heating efficiency is fairly high. Even when dropping the density by a factor of two, almost the same heating efficiency results. Only when dropping down to densities more characteristic for the current generation of tokamak devices, heating is less promising because of the relatively small minor radius. However, for current drive studies, going to lower densities is beneficial. For $\mathrm{H}$ concentrations in the range of $5 \%-15 \%$, minority $\mathrm{H}$ heating in $\mathrm{D}$ or ${ }^{4} \mathrm{He}$ plasmas is a very efficient heating scheme for the expected high density W7-X parameters $\left(\mathrm{n}_{\mathrm{e}}=2 \times 10^{20} \mathrm{~m}^{-3}, \mathrm{~T}_{0}=3 \mathrm{keV}\right)$. For hydrogen concentrations up to $10 \%$, the absorption in a full transit over the plasma exceeds $90 \%$ of the incoming power, as can be seen in Fig. 8(a). At low H concentrations, majority $\mathrm{D}$ or ${ }^{4} \mathrm{He}$ second harmonic heating is extremely efficient (up to $80 \%$ when the $\mathrm{H}$ concentration approaches zero) due to the large density. Electron heating represents a modest and fairly constant fraction of $\sim 20 \%$ of the launched power. The deposition profile is broad for all species (see Fig. 8(b)). The $\mathrm{H}$ minority heating scheme ensures good bulk heating in a wide range of $\mathrm{k}_{/ /}$values with full transit absorption of $90 \%-100 \%$ of the incoming power, except for very low $\mathrm{k}_{/ /}$values $\left(\mathrm{k}_{/ /} \mathrm{l}<3 \mathrm{~m}^{-1}\right)$. Only for large $\mathrm{H}$ concentrations where electron heating competes with $\mathrm{H}$ heating, the
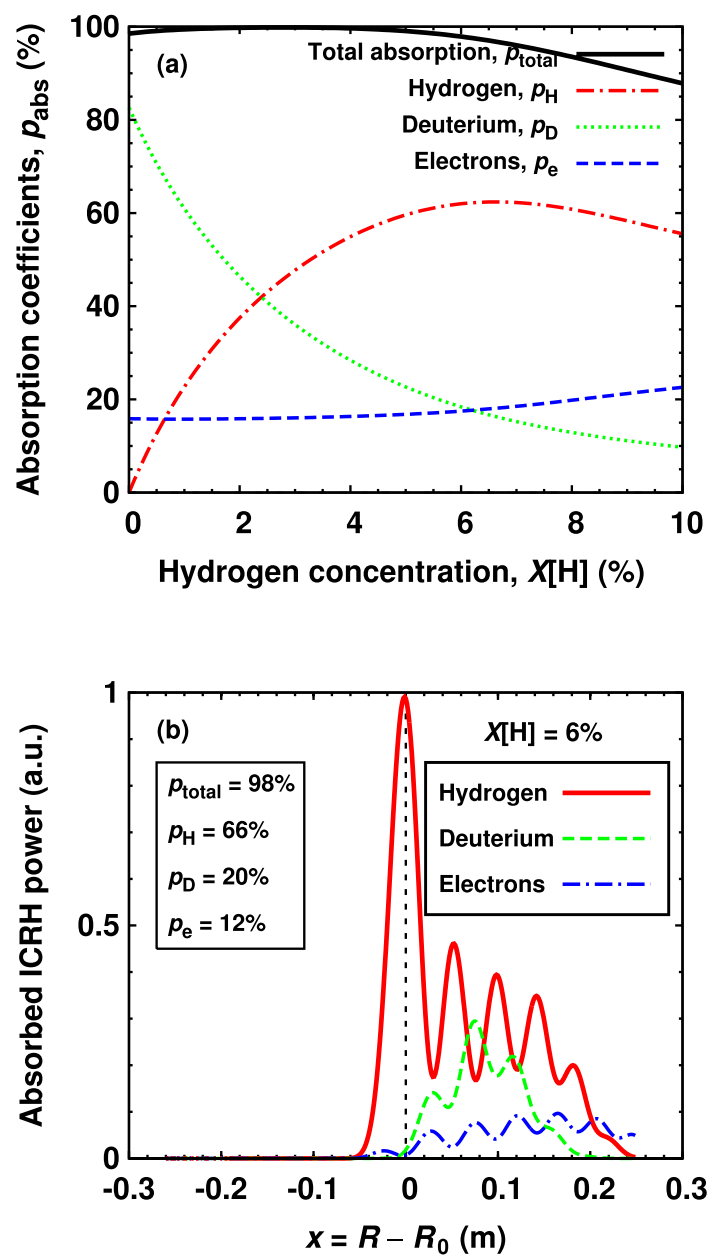

FIG. 8. (a) Power repartition among the different plasma species for the fundamental $\mathrm{H}$ heating scenario at $38 \mathrm{MHz}$ and $\mathrm{B}_{0}=2.5 \mathrm{~T}$. (b) Power deposition profiles for the fundamental $\mathrm{H}$ scenario at a $\mathrm{H}$ concentration $\mathrm{n}_{\mathrm{H}} / \mathrm{n}_{\mathrm{e}}=6 \%$. restrictive $\mathrm{k}_{/ /}$region slightly extends to higher $\left|\mathrm{k}_{/ /}\right|$values. Operating either at high density or high temperature ensures higher single pass absorption. At low core density $\left(2 \times 10^{19} \mathrm{~m}^{-3}\right)$ and/or temperature $(1 \mathrm{keV})$, the single pass absorption drops to half of the value observed at high density and temperature.

Inverted scenarios such as ${ }^{3} \mathrm{He}$ minority in $\mathrm{H}$ can also be used but could pose difficulties because of edge power deposition as discussed above. Estimates show that for the case of ${ }^{3} \mathrm{He}$ minority in $\mathrm{H}$ at $25 \mathrm{MHz}$ and $\mathrm{B}=2.46 \mathrm{~T}$, between $15 \%$ and $20 \%$ of the launched power could be lost in the plasma edge resulting in a reduced efficiency of the heating scheme and possibly localized deposition of power at first wall components. On the other hand, very localized central ${ }^{3} \mathrm{He}$ heating can be realised at modest ${ }^{3} \mathrm{He}$ concentrations of $2 \%$, with full transit absorption levels of about $70 \%$ of the incoming power.

High energy tails can only be created when working at low $\left(1-2 \times 10^{19} \mathrm{~m}^{-3}\right)$ densities. MeV minority $\mathrm{H}$ tails can easily be created at low density and low minority concentration provided the ICRH power density level is sufficiently high calculations adopting a generalized version ${ }^{7}$ of the method proposed by $\mathrm{Stix}^{8}$ to solve the relevant Fokker-Planck equation for the ICRH induced energetic particles show that $1 \mathrm{MeV}$ ions are 10 orders of magnitude more abundant when $\mathrm{P}_{\mathrm{ICRH}}=1 \mathrm{MWm}^{-3}$ than at $0.2 \mathrm{MWm}^{-3}$. High density operation renders tail formation hard and would require unrealistically high power density levels.

Current drive is most efficient at low density and low $\left|\mathrm{k}_{/ /}\right|$, as can be seen in Fig. 9. At core densities around $10^{20} \mathrm{~m}^{-3}, 30-40 \mathrm{kA}$ can be driven per MW. This efficiency drops to less than half of that value in the case of high density operation $\left(4 \times 10^{20} \mathrm{~m}^{-3}\right)$.

At present, the theoretical knowledge of wave propagation and damping in stellarators is rather limited. The conclusions in this section are therefore of a preliminary nature, although it is reasonable to believe that a detailed knowledge of the geometry of the system is not needed for the calculation of the wave patterns in scenarios with single pass absorption. It is equally likely that scenarios with poor absorption

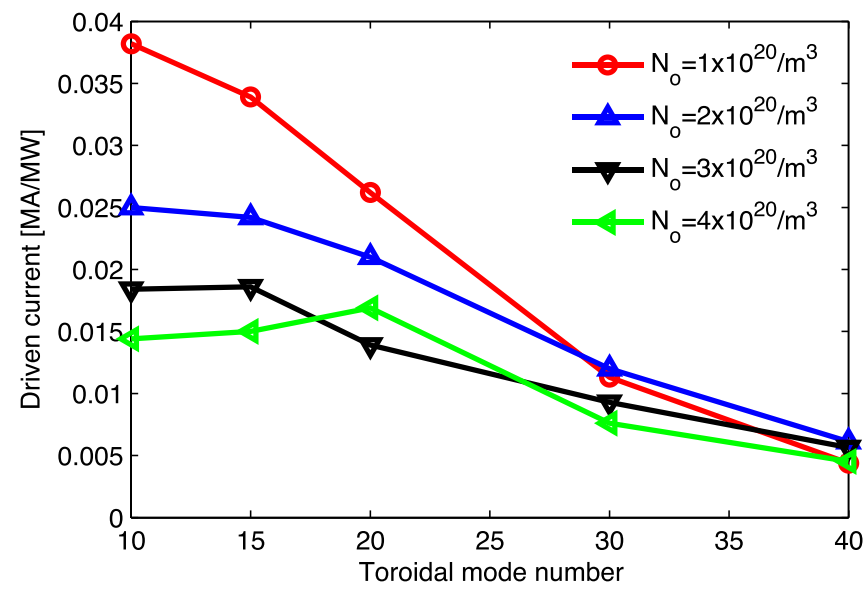

FIG. 9. Fast wave electron current drive efficiency in MA/MW ICRH power launched for a $\mathrm{H}$ concentration $\mathrm{n}_{\mathrm{H}} / \mathrm{n}_{\mathrm{e}}=20 \%$ at $\mathrm{T}_{0}=3 \mathrm{keV}$. 
are ill described by presently available "stellarator mockups," and the same holds for other than qualitative predictions on current drive efficiencies and tail formation. Checking the results of current and future calculations with the outcome of the experiment will be an important part of ICRH physics studies.

\section{ELECTROMAGNETIC DESIGN}

The geometry of these compact antennae in the narrow port has been optimized for the best coupling conditions to a reference plasma density profile. ${ }^{3}$ The antenna plug-in designed for operation between $25 \mathrm{MHz}$ and $38 \mathrm{MHz}$ consists of a pair of single straps, each of them tuned by a commercially available vacuum capacitor at the rear of the

(a)
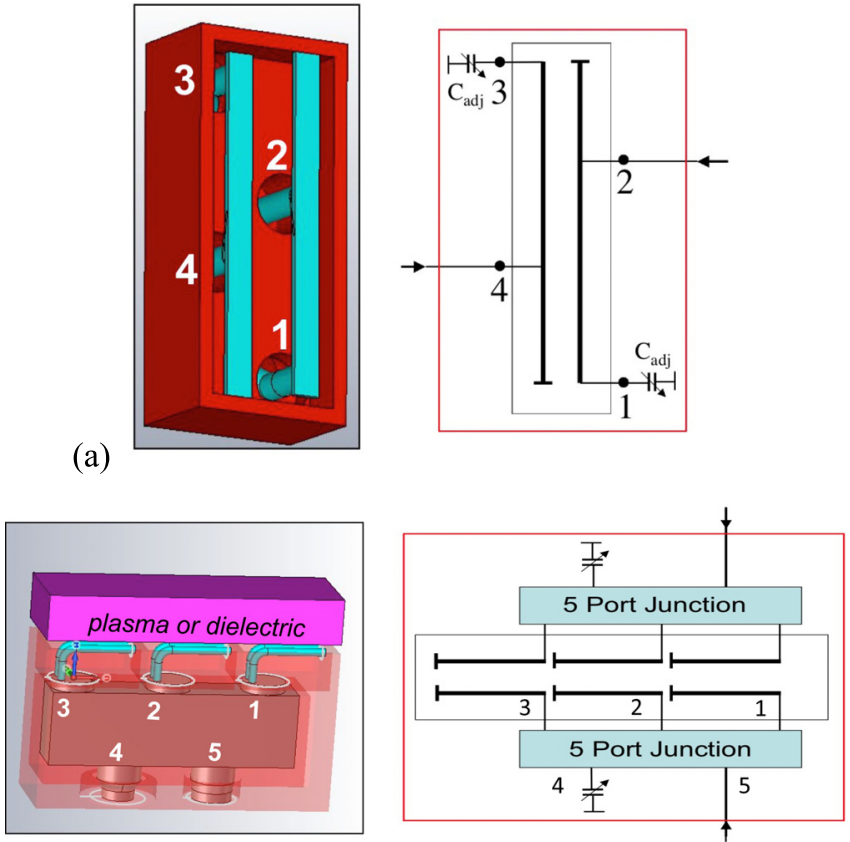

(b)

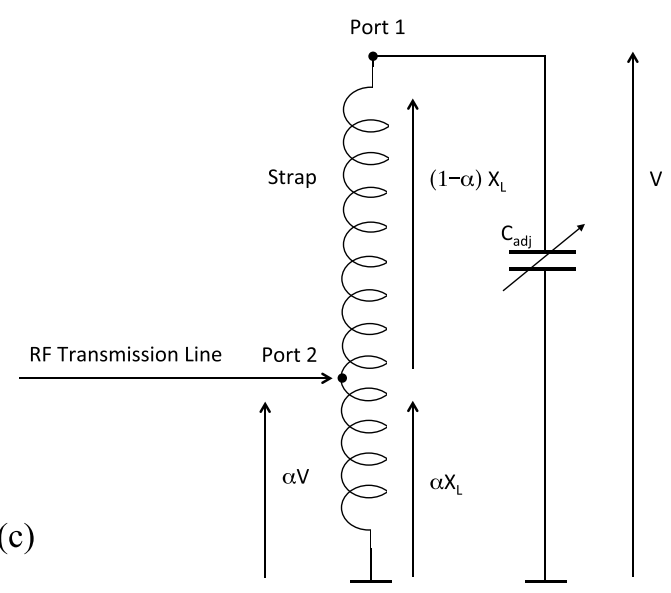

FIG. 10. (a) Schematic representation of the antenna plug-in for the frequency band 25-38 MHz as a 4-port junction. (b) Schematic representation of the antenna plug-in for the frequency band around $76 \mathrm{MHz}$. Each set of 3 straps is fed in parallel by 3 outputs of the 5 port junction. (c) Principle of pre-matching using a tuned resonator with tap feed. The maximal voltage $\mathrm{V}$ in the system is located at the capacitor and the maximum feeding line voltage is reduced to $\alpha \mathrm{V}<\mathrm{V}$. $\mathrm{X}_{\mathrm{L}}$ is the total strap inductive reactance and the tap is placed at a position such that the reactance between tap and grounding is $\alpha \mathrm{X}_{\mathrm{L}}$. antenna housing box (Fig. 10(a)). To reduce the maximum voltage on the system, a pre-matching has been implemented by connecting the RF transmission lines at an intermediate position on each poloidal strap (referred to as "tap" in what follows), which on one side is connected to the capacitor and grounded to the antenna box at the other end. The second variant, optimized for operation in a frequency band around the central frequency of $76 \mathrm{MHz}$, consists of a pair of poloidal strap triplets fed by a tunable 5-port junction (Fig. 10(b)). The 5-port junction with its tuning vacuum capacitor is also placed at the rear of the antenna box in the antenna port, similar to the 4-port junction proposed for the ITER ICRH antenna. ${ }^{9}$ A feeding-matching system using the two $2 \mathrm{MW}$ ICRH generators $(25-38 \mathrm{MHz}$ band) of TEXTOR allows a flexible antenna phasing with as applications: (0 0$)$ phasing for Ion Cyclotron Wall Conditioning, $(0 \pi)$ phasing for heating/ fast particle generation, and $(0 \pm \pi / 2)$ for heating with some current drive. The $(0 \pm \pi / 2)$ phasing has a larger coupling than the $(0 \pi)$ phasing due to its lower $\left|\mathrm{k}_{/ /}\right|$excitation, as discussion in Sec. II A. Other phasings are evidently possible as well. For plasma operation without ICRH, the antenna can be almost completely withdrawn into the port, away from the plasma boundary, to reduce the heat loads from the plasma and ECRH stray radiation. This paper will focus on the design of the two strap antenna for the lower frequency band 25-38 MHz.

An approximate equivalent electrical schema of each antenna strap (with length $1_{\text {strap }}<\lambda / 4, \lambda$ being the wavelength of the launched RF waves) together with the tuning capacitor consists of an inductance in parallel with a variable capacitor, as shown in Fig. 10(c). For a given input voltage to the strap, the maximum voltage in the RF transmission lines is determined by the pre-matching, done by positioning the "tap" at a fraction $\alpha \mathrm{L}$ from of the total strap inductance $\mathrm{L}$ with $0<\alpha<1$. The voltage at the position of the tap is then $\alpha \mathrm{V}$, with $\mathrm{V}$ the maximum allowable voltage in the antenna system.

The antenna box consists of a 4-port network (see Fig. 10(a)) which is modeled by the TOPICA ${ }^{10}$ or MWS $^{11}$ codes. TOPICA uses the plasma density profile as provided by the W7-X team in front of the antenna. This is not possible in MWS, and instead a stratified dielectric profile ${ }^{12}$ is used to mimic the density profile for coupling simulations and comparison of the results obtained with TOPICA. Optimisation of the design proceeds as follows. For each variation in the geometry of the antenna box (strap width, distance between the straps, antenna box depth, etc.), the $4 \times 4$ scattering matrix describing the electromagnetic behaviour of the antenna loaded by the plasma reference profile is obtained from these codes.

From the scattering matrix $\mathrm{S}$, we derive the admittance matrix $\mathrm{Y}$, which results in a system of 4 equations linking the voltages and currents $V_{i}$ and $I_{i}$ at the ports $1,2,3,4$. To be able to solve this system of the 8 unknowns $\mathrm{I}_{1 \ldots 4}$ and $\mathrm{V}_{1 \ldots 4}$, we impose that the amplitudes of the currents in port 1 and port 3 are equal for a chosen phasing $\Delta \phi,\left|\mathrm{I}_{1}\right|=\left|\mathrm{I}_{3}\right|$ with $\mathrm{I}_{1}=\mathrm{I}_{3} \exp (\mathrm{i} \Delta \phi)$. Then, we make use of the relation between voltage and current at the capacitors: $\mathrm{I}_{1,3}=\mathrm{V}_{1,3}(\mathrm{i}$ $\left.\omega \mathrm{C}_{\mathrm{adj}}\right)$. We have now a system of equations that allows to 


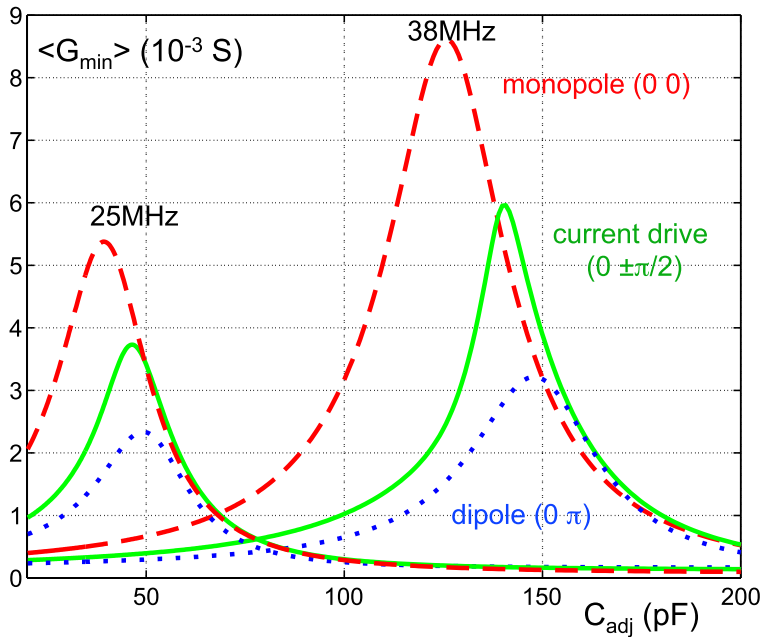

FIG. 11. Evolution of $\left\langle\mathrm{G}_{\min }\right\rangle$ vs. $\mathrm{C}_{\text {adj }}$ for $25 \mathrm{MHz}$ and $38 \mathrm{MHz}$. The dashed curves correspond to $(00)$ phasing, the full ones to $(0 \pm \pi / 2)$ phasing and the dotted ones to $(0 \pi)$ phasing. The peak value of $\left\langle\mathrm{G}_{\min }\right\rangle$ determines the best tuning for the capacitor $\mathrm{C}_{\text {adj,max }}$.

determine $\mathrm{I}_{2}, \mathrm{I}_{4}, \mathrm{~V}_{2}$ and $\mathrm{V}_{4}$ and thus also the delivered active power $\mathrm{P}_{2}$ and $\mathrm{P}_{4}$ at ports 2 and 4 of the 4-port junction. To determine the value of $\mathrm{C}_{\mathrm{adj}}=\mathrm{C}_{\mathrm{adj}, \max }$ which produces the best pre-matching compatible with the equality $\left|\mathrm{I}_{1}\right|=\left|\mathrm{I}_{3}\right|$ and their difference in phasing, a scan in $\mathrm{C}_{\mathrm{adj}}$ is made. For a given frequency and phasing of the straps, the value $\mathrm{C}_{\mathrm{adj}, \max }$ is the value of $\mathrm{C}_{\mathrm{adj}}$ for which the mean minimum conductance of feeding lines 2 and $4,\left\langle\mathrm{G}_{\min }\right\rangle$ (defined as $\left\langle\mathrm{G}_{\min }\right\rangle=\left(\mathrm{G}_{\min , 2}+\mathrm{G}_{\min , 4}\right) / 2$ with $\mathrm{G}_{\min , \mathrm{i}}=2 \mathrm{P}_{\mathrm{i}} / \mathrm{V}^{2}{ }_{\max , \mathrm{i}}$, where $\mathrm{V}_{\max , i}$ is the anti-node voltage on line i) reaches a maximum, as shown on Fig. 11, presenting an example where we varied the strap width.

Repeating this procedure for the phasings of interest and all frequencies in the band then results in a set of $\mathrm{C}_{\mathrm{adj}, \max } \mathrm{val}-$ ues versus frequency for the various phasings, summarized in Fig. 12. The total active power $\mathrm{P}_{\text {tot }}=\mathrm{P}_{2}+\mathrm{P}_{4}$ can then be obtained as a function of the frequency $f$ solving the set of equations using at each frequency the corresponding value of $\mathrm{C}_{\mathrm{adj}, \mathrm{max}}$ found previously. This allows to adjust the capacitance range needed to cover the frequency band. Vacuum capacitor modelling and experimental tests will be undertaken to test the effective capacitance range of the capacitor in its housing. If necessary, the strap width will be adapted.

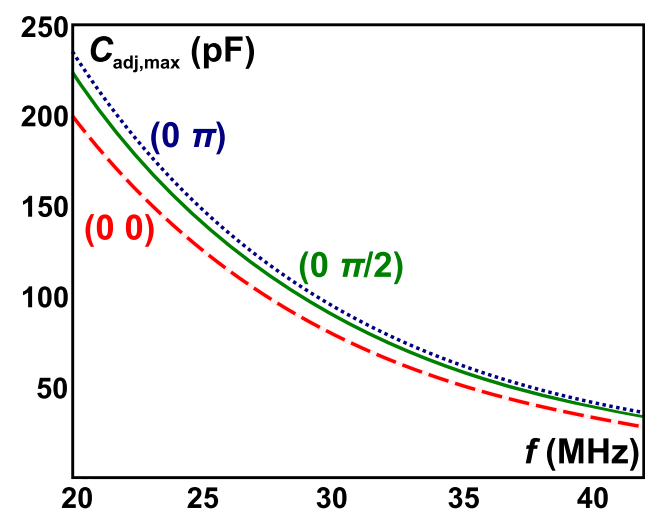

FIG. 12. Plot of $\mathrm{C}_{\mathrm{adj}}$ versus frequency for the different antenna phasings.
Due to the tap feed, the maximum voltage is occurring at the tuning capacitor, as explained above. To determine the maximum power capability of the antenna system, we have to take into account the maximum voltage $\mathrm{V}_{\mathrm{C}, \max }$ and current $\mathrm{I}_{\mathrm{C}, \max }$ specifications of the capacitor. These were set at $\mathrm{I}_{\mathrm{C}, \max }=800 \mathrm{~A}$ and $\mathrm{V}_{\mathrm{C} \text {, max }}=40 \mathrm{kV}$. The limitations in power are then determined either by $\mathrm{V}_{\mathrm{C}, \max }$ or $\mathrm{I}_{\mathrm{C}, \max } /\left(\omega \mathrm{C}_{\mathrm{adj}}\right)$ depending on which value is the smallest. This is illustrated in Figs. 13(a)-13(c) (assuming a strap width of $90 \mathrm{~mm}$ ). Fig. 13(a) shows the evolution of the voltages $V_{1}$ to $V_{4}$ and Fig. 13(b) shows the evolution of the currents $I_{1}$ to $I_{4}$ as a
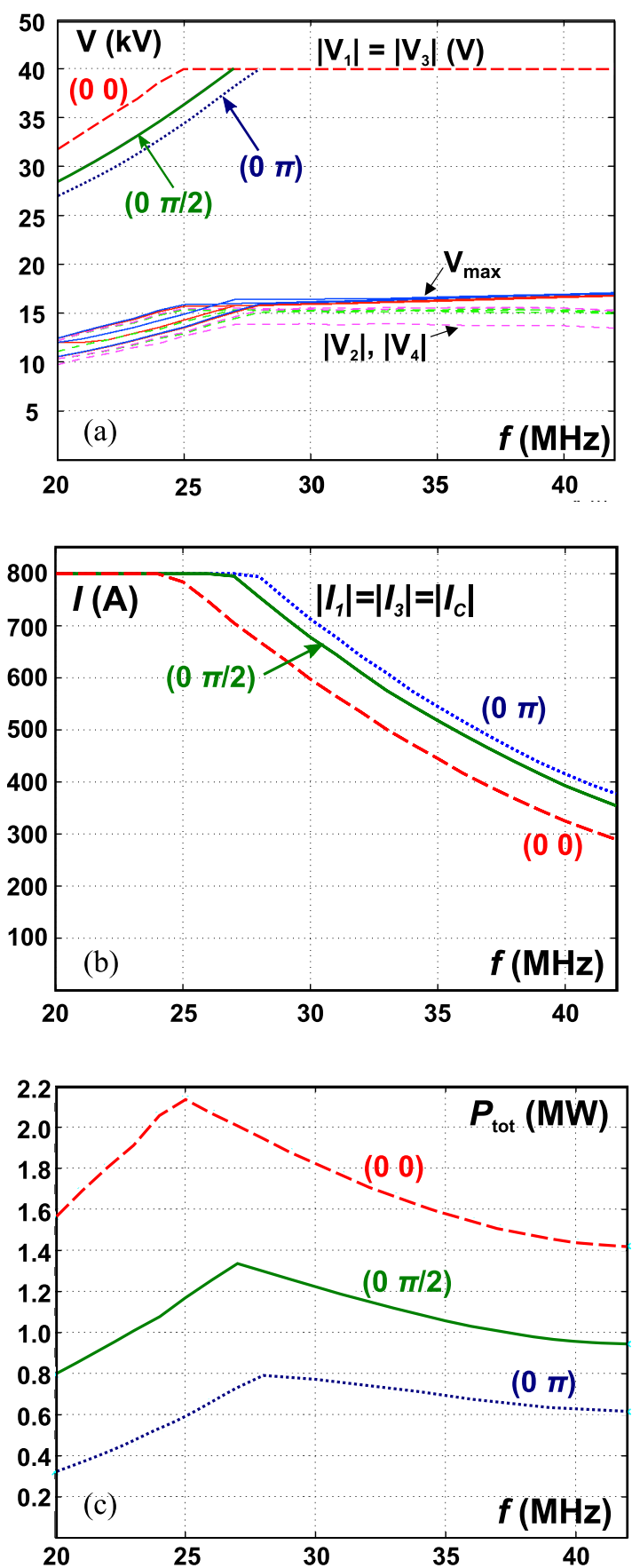

FIG. 13. (a) Evolution of the voltages $\mathrm{V}_{1}$ to $\mathrm{V}_{4}$ as a function of frequency (strap width $90 \mathrm{~mm}$ ). (b) Evolution of the currents $I_{1}$ to $I_{4}$ as a function of frequency (strap width $90 \mathrm{~mm}$ ). (c) Evolution of the total coupled power as a function of frequency (strap width $90 \mathrm{~mm}$ ). 

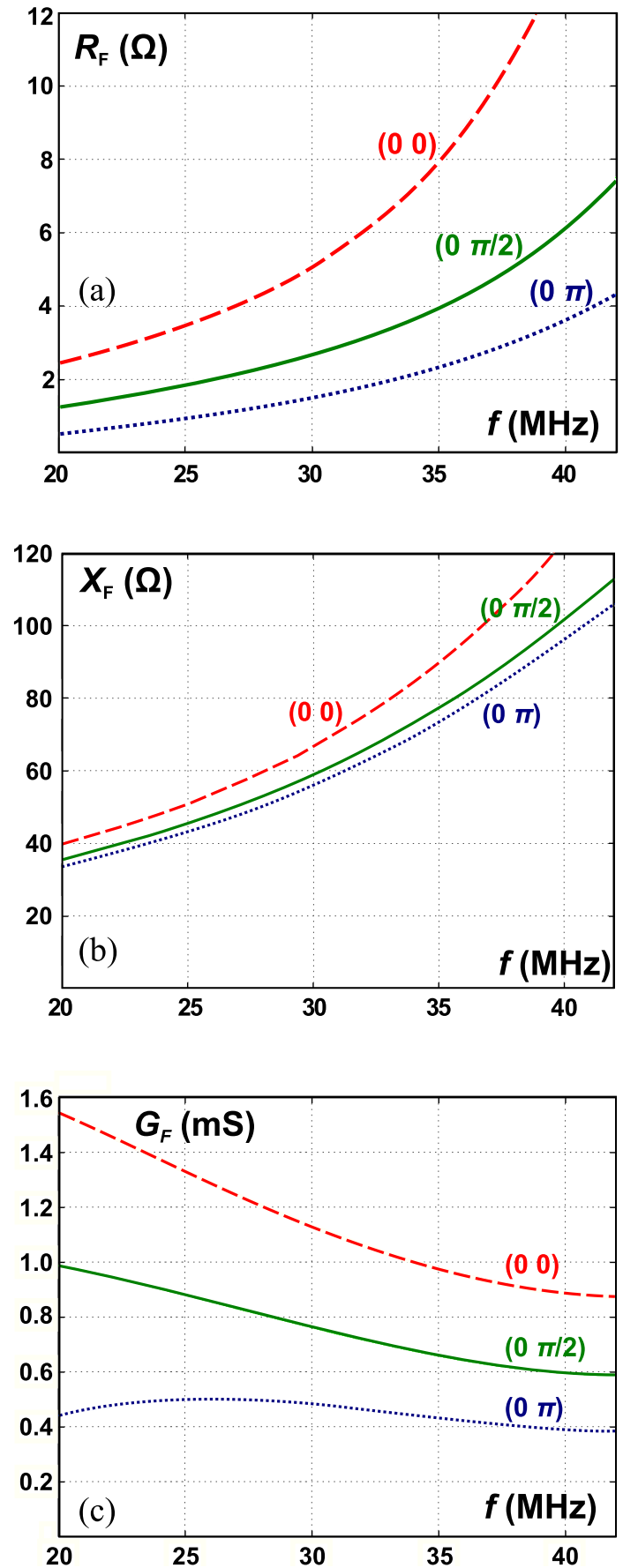

FIG. 14. (a) Evolution of $R_{f}$ versus frequency (strap width $90 \mathrm{~mm}$ ). (b) Evolution of $X_{f}$ versus frequency (strap width $90 \mathrm{~mm}$ ). (c) Evolution of $\mathrm{G}_{\mathrm{f}}$ versus frequency (strap width $90 \mathrm{~mm}$ ).

function of frequency. Fig. 13(a) shows clearly the beneficial effect of the tap feed, reducing the maximum voltage for $\mathrm{V}_{2}$ and $\mathrm{V}_{4}$ to $\sim 15 \mathrm{kV}$ in this case (for a tap positioned at $46 \%$ of the total strap inductance). A plot of the evolution of the maximum power versus frequency obtained in this way shows a maximum (further on called "angular point," see Fig. 13(c)), and the curve is divided in two parts: left of the maximum, limited by $\mathrm{I}_{\mathrm{C}, \max }$ (and then $\left|\mathrm{V}_{1,3}\right|<\mathrm{V}_{\mathrm{C} \text {,max }}$ ) and right of the maximum, limited by $\mathrm{V}_{\mathrm{C} \text {,max }}$ (and then $\left.\left|\mathrm{I}_{1,3}\right|<\mathrm{I}_{\mathrm{C}, \max }\right)$.

The behaviour of $\mathrm{P}_{\text {tot }}$ versus frequency $\mathrm{f}$ at both sides of the angular point can be explained by the mean strap impedance $\mathrm{Z}_{\mathrm{f}}$ at the connections with the capacitors (ports 1 and 3), defined as

$$
\mathrm{Z}_{\mathrm{f}}=1 / \mathrm{Y}_{\mathrm{f}}=\mathrm{R}_{\mathrm{f}}+\mathrm{i} \mathrm{X}_{\mathrm{f}}=2\langle\mathrm{P}\rangle /\left|\mathrm{I}_{1,3}\right|^{2},
$$

with $\langle\mathrm{P}\rangle=\left(\mathrm{P}_{2}+\mathrm{P}_{4}\right) / 2, \mathrm{P}_{2}$ and $\mathrm{P}_{4}$ being the power delivered to ports 2 and 4 by the feeding lines and $I_{1}$ and $I_{3}$ being the current at ports 1 and 3. The strap conductance is defined as $\operatorname{Re}\left(\mathrm{Y}_{\mathrm{f}}\right)=\mathrm{G}_{\mathrm{f}} \sim \mathrm{R}_{\mathrm{f}} / \mathrm{X}_{\mathrm{f}}^{2}\left(\mathrm{R}_{\mathrm{f}}^{2} \ll \mathrm{X}_{\mathrm{f}}^{2}\right)$. $\mathrm{P}_{\text {tot }}$ varies as $\mathrm{R}_{\mathrm{f}} \mathrm{I}_{\mathrm{C}, \max }^{2} / 2$ for frequencies smaller than the angular point (which corresponds to $\mathrm{I}_{\mathrm{C}, \text { max }}=\mathrm{V}_{\mathrm{C}, \text { max }} \omega \mathrm{C}_{\mathrm{adj}, \text { max }}$ ) and as $\mathrm{G}_{\mathrm{f}} \mathrm{V}_{\mathrm{C}, \text { max }} / 2$ for higher frequencies. Note that both $R_{f}$ and $X_{f}$ increase with increasing frequency $f$ and are decreasing with the strap width but not in the same way. This results in an increase of $G_{f}$ with decreasing frequency and increasing strap width. This is illustrated in Figs. 14(a)-14(c), where we show respectively, $R_{f}$, $\mathrm{X}_{\mathrm{f}}$, and $\mathrm{G}_{\mathrm{f}}$ as a function of frequency (for the strap width of $90 \mathrm{~mm}$ ). Therefore, when the strap width increases, $P_{\text {tot }}$ decreases for frequencies below the frequency corresponding to the angular point and increases at the other side of this point as seen in Fig. 15. The optimization then consists in selecting a strap width that avoids a significant reduction of the power at $25 \mathrm{MHz}$ and has a beneficial influence at $38 \mathrm{MHz}$. We have selected a strap width of $90 \mathrm{~mm}$ (Fig. 15).

Matching the generators to this antenna can be done with a traditional system using line stretchers and stubs (Fig. 16). Slow coupling variations can be compensated using, in addition, the automatic tuning system of TEXTOR. ${ }^{13}$ As the straps in the antenna box are closely packed there is a large mutual coupling between the straps. This leads to a large active power imbalance between ports 2 and 4, needed to obtain the same amplitude of the strap currents in the case of $(0 \pm \pi / 2)$ phasing.

To minimize their effect on the matching circuit and to equalize the power supplied by both generators for $(0 \pm \pi / 2)$ phasing a decoupler system ${ }^{14}$ is included, positioned near the voltage anti-node. The effect of the decoupler is to provide a reactive admittance matrix $\mathrm{Y}_{\mathrm{dec}}$ that is added to the $2 \times 2$

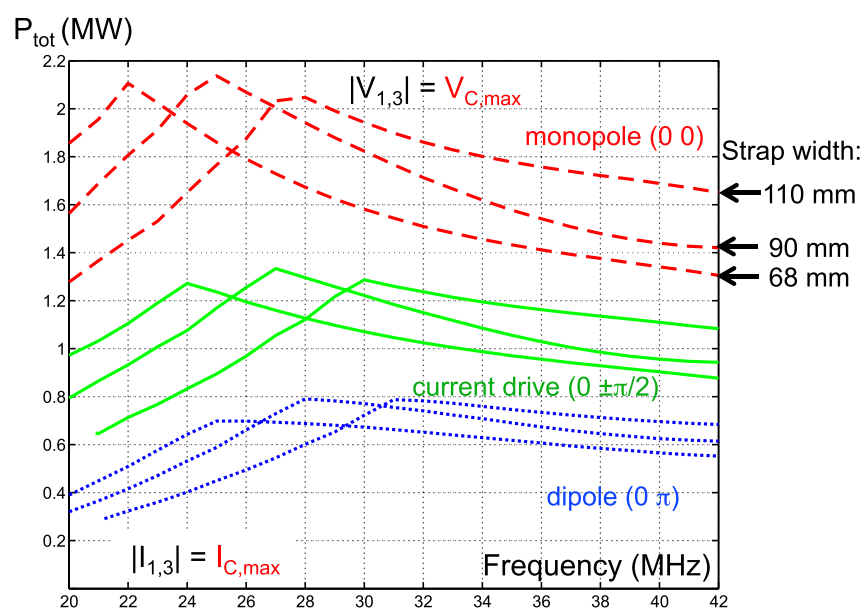

FIG. 15. Evolution of the total coupled power $\mathrm{P}_{\text {tot }}$ versus frequency for different strap widths: $68 \mathrm{~mm}, 90 \mathrm{~mm}$ and $110 \mathrm{~mm}$. The dashed curves correspond to $(00)$ phasing, the full ones to $(0 \pm \pi / 2)$ phasing and the dotted ones to $(0 \pi)$ phasing. A strap width of $90 \mathrm{~mm}$ offers best coupling for both 25 and $38 \mathrm{MHz}$. 


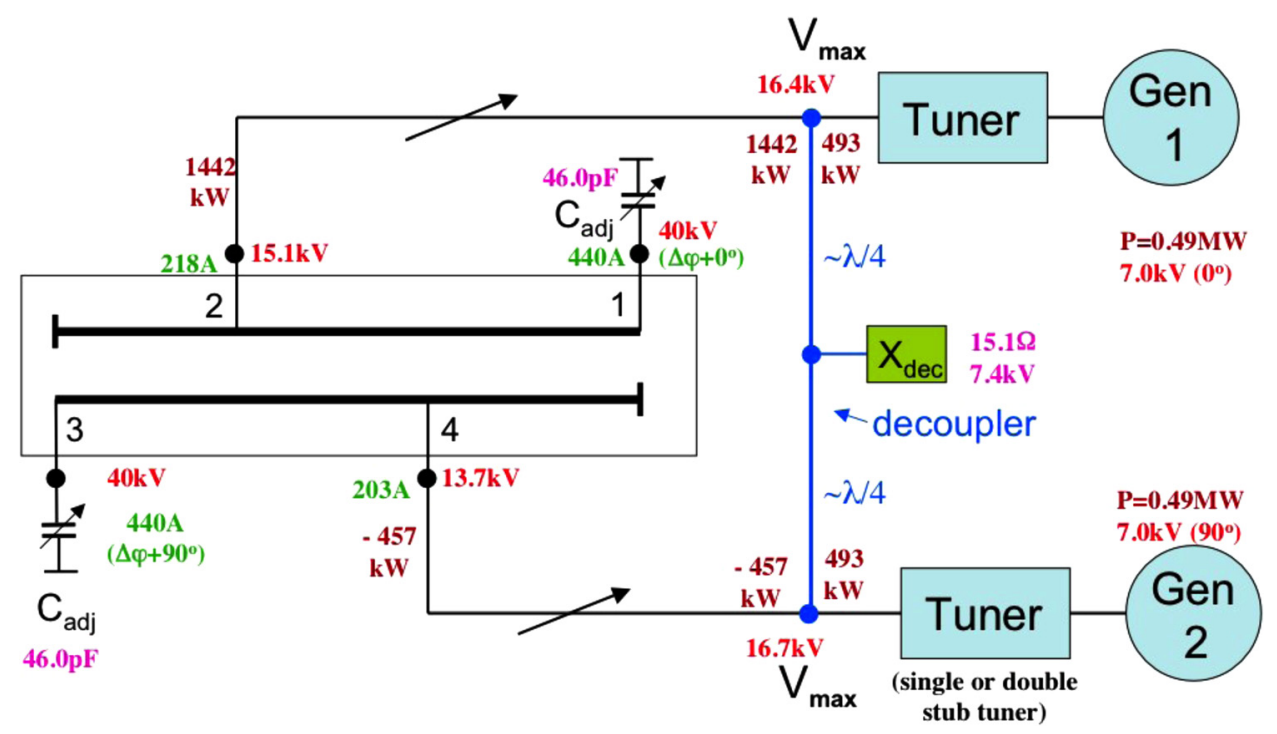

FIG. 16. Matching and decoupler network, including the values for $\mathrm{C}_{\mathrm{adj}, \max }$, powers, voltages and currents at $38 \mathrm{MHz}$ for $(0 \pm \pi / 2)$ phasing (for a strap width of $90 \mathrm{~mm}$ ).

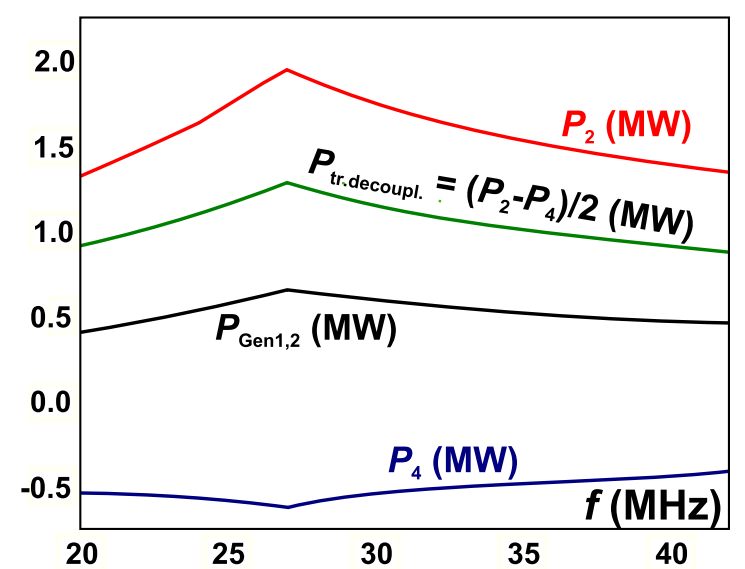

FIG. 17. Illustration of the effect of the decoupler on equalizing the powers supplied by the generators. The large imbalance between $\mathrm{P}_{2}$ and $\mathrm{P}_{4}$ is not seen by the generators because of the power $\left(\mathrm{P}_{2}-\mathrm{P}_{4}\right) / 2$ flowing through the decoupler.

admittance matrix $\mathrm{Y}_{\mathrm{m}}$ of the antenna at the positions $\mathrm{V}_{\max 2,4}$ aiming at neutralizing the reactive mutual coupling terms $\operatorname{Im}\left(\mathrm{Y}_{\mathrm{m}}(1,2)\right) \cong \operatorname{Im}\left(\mathrm{Y}_{\mathrm{m}}(2,1)\right)$ and thus equalizing the powers that are provided by the generators without coupling between them and their matching circuits. The decoupler (Fig. 16) consists of 2 line sections of length $\sim \lambda / 4$ (at mid-band) connected to an adjustable reactance $X_{\mathrm{dec}}$. The values of current, voltage, and power at different locations of the matching-decoupling circuit are indicated on Fig. 16 for $(0 \pi / 2)$ phasing at $38 \mathrm{MHz}$ as deduced from the scattering matrix calculated by TOPICA. The evolution versus frequency of the active powers $\mathrm{P}_{1}$ and $\mathrm{P}_{2}$ delivered, respectively, at ports 2 and 4 , together with the power $P_{\text {gen } 1,2}$ delivered by both generators and the active power exchanged between both heating lines by the decoupler $\mathrm{P}_{\text {tr,decoupl }}$ are shown for the $(0 \pi / 2)$ phasing in Fig. 17. Note that the active power $\mathrm{P}_{4}$ is even negative: port 4 receives a net power from port 2 to maintain the same current amplitude on the two straps as a result of the large mutual coupling.

For the upper part of the frequency band $(\sim 76 \mathrm{MHz})$ the conceptual design of another plug-in has been carried out. It consists of two triplets of short straps, whereby the individual straps of each of the triplets is fed in parallel by means of a 5-port junction as shown in Fig. 18. This junction is analogous to the 4-port junction used for the ICRH antenna of ITER ${ }^{15}$ but with the extra capability of fine frequency tuning. This junction induces about the same current in each short strap of the triplet and acts as a single frequency filter which is tuned by its geometry and a variable tuning capacitor $\mathrm{C}_{\mathrm{T}}$

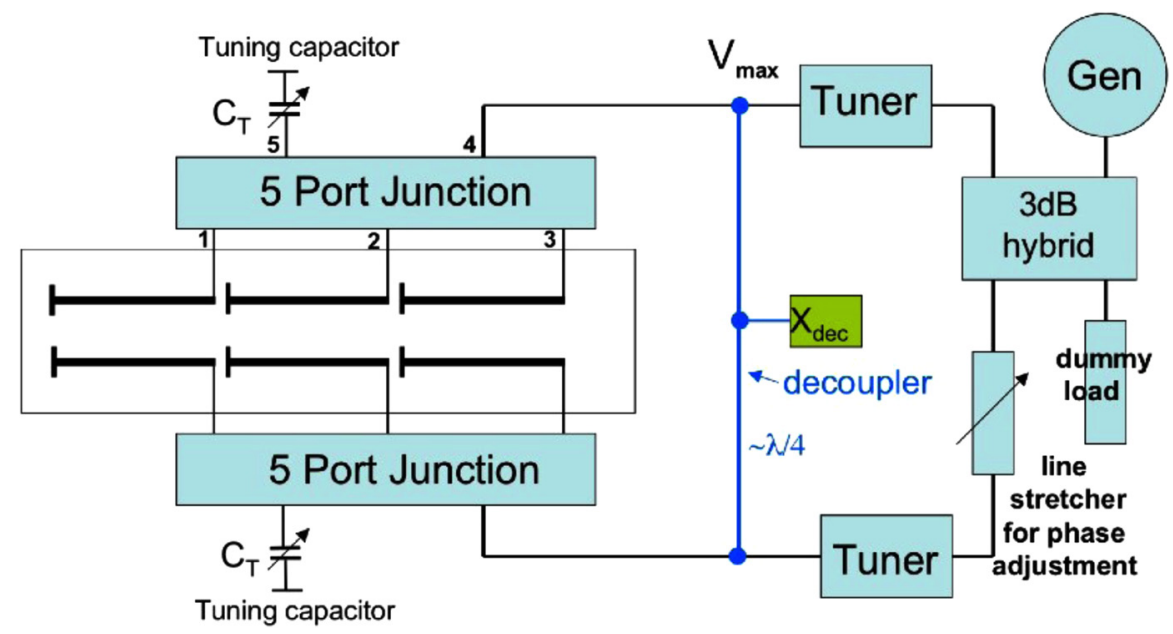

FIG. 18. Matching layout for the $76 \mathrm{MHz}$ antenna. 


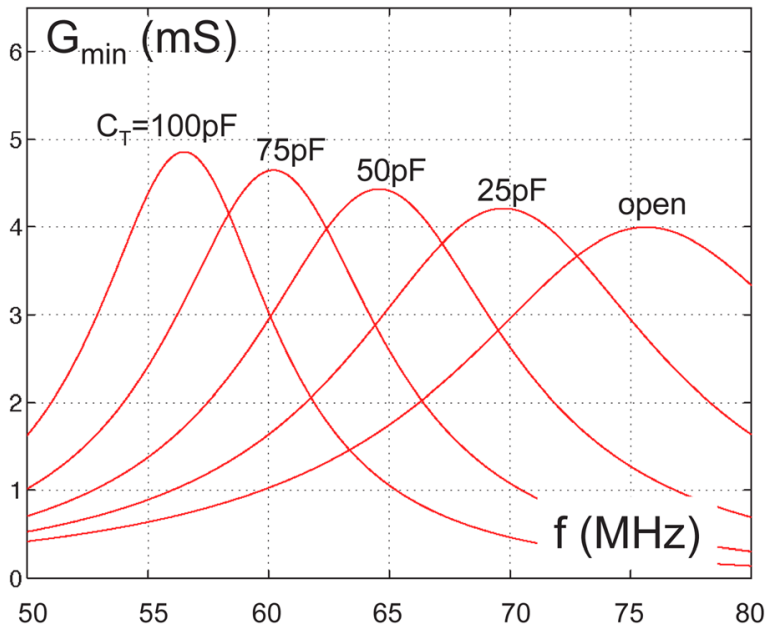

FIG. 19. Illustration of the shift in the frequency response of the mean input conductance at port 4 , using a tuning capacitor $\mathrm{C}_{\mathrm{T}}$ at port 5 of the junction.

connected to its fifth port. It provides a prematching around its tuning frequency. Fig. 19 shows the ability of $\mathrm{C}_{\mathrm{T}}$ to shift the frequency response curve of the mean input conductance at port 4 of both junctions. The matching layout is similar as for the first frequency band but with appropriate components. If only one $76 \mathrm{MHz}$ generator is used (case of Fig. 18), this system requires in addition a $3 \mathrm{~dB}$ splitter/coupler hybrid together with a line stretcher to provide for a flexible phasing of the toroidal pair of strap triplets.

\section{MECHANICAL DESIGN FOR THE PLUG-IN FOR THE 25-38 MHZ BAND}

The ICRH antenna designed for $\mathrm{W} 7-\mathrm{X}$ will be installed in the equatorial plane in module 3 at port AEE31. A design view on the global system with standard plasma is presented in Fig. 20. More details of the antenna system are shown in Fig. 21 where the shielding of the antenna box and the plasma itself are removed. The following requirements need to be integrated in the design:

- Installation of the antenna assembly in W7-X without invessel access

- Two transmission lines to deliver the ICRH power
- Positioning system, to ensure optimal coupling to different plasma configurations

- Provisions to install a tuning capacitor

- Water cooling during long pulse (up to $30 \mathrm{~min}$ ) dc plasma operation

- Diagnostics for measurement of ICRH power and edge plasma conditions

\section{A. Installation of the antenna system avoiding In-vessel access}

The ICRH antenna is designed such that it can be integrated at a port without mechanical support from the inner vessel. Therefore, the ICRH antenna unit is mounted on a table and can be moved on pre-aligned rails. The center of gravity indicated in the principal setup shown in Fig. 20 is located outside the AEE31 flange, which will allow an easy transportation from the assembly hall to the W7-X torus. The basic support structure with rails is aligned to an axis defined by the port centers of the inner (plasma) and outer (cryostat) vessel. Sufficient clearance is foreseen in the port such that the system will be able to cope with displacements of the inner vessel with respect to the cryostat port during W7-X pump down.

\section{B. Adapting to different plasma shapes}

Different magnetic field configurations are foreseen for experiments on $\mathrm{W} 7-\mathrm{X}$, each leading to a different plasma shape. The distance between the Last Closed Magnetic Surface (LCMS) and the outside edges of the antenna box in parking position for the most extreme plasma shapes can be up to $330 \mathrm{~mm}$. The shape of the antenna box and straps has been optimized for plasmas corresponding to the so-called standard field configuration. This results in an antenna box and strap surface structure with a poloidal and toroidal curvature, see Fig. 22. In this case, the distance between any point on the straps and LCMS will be $50 \mathrm{~mm}$, whereby the antenna box is positioned $257 \mathrm{~mm}$ into the inner vessel with respect to the parking position of the antenna in the port. For all other configurations, the width of the gap between straps and LCMS will vary over the strap surface, and this will

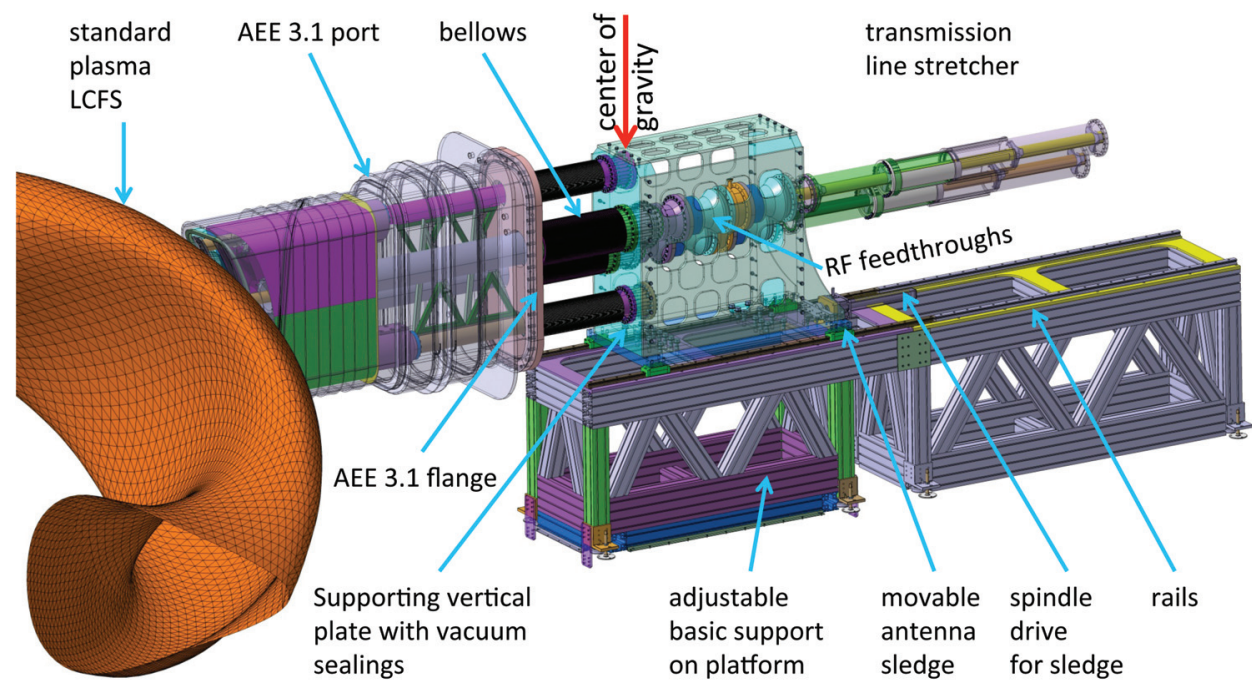

FIG. 20. Outline mechanical design of the antenna system for W7-X. 


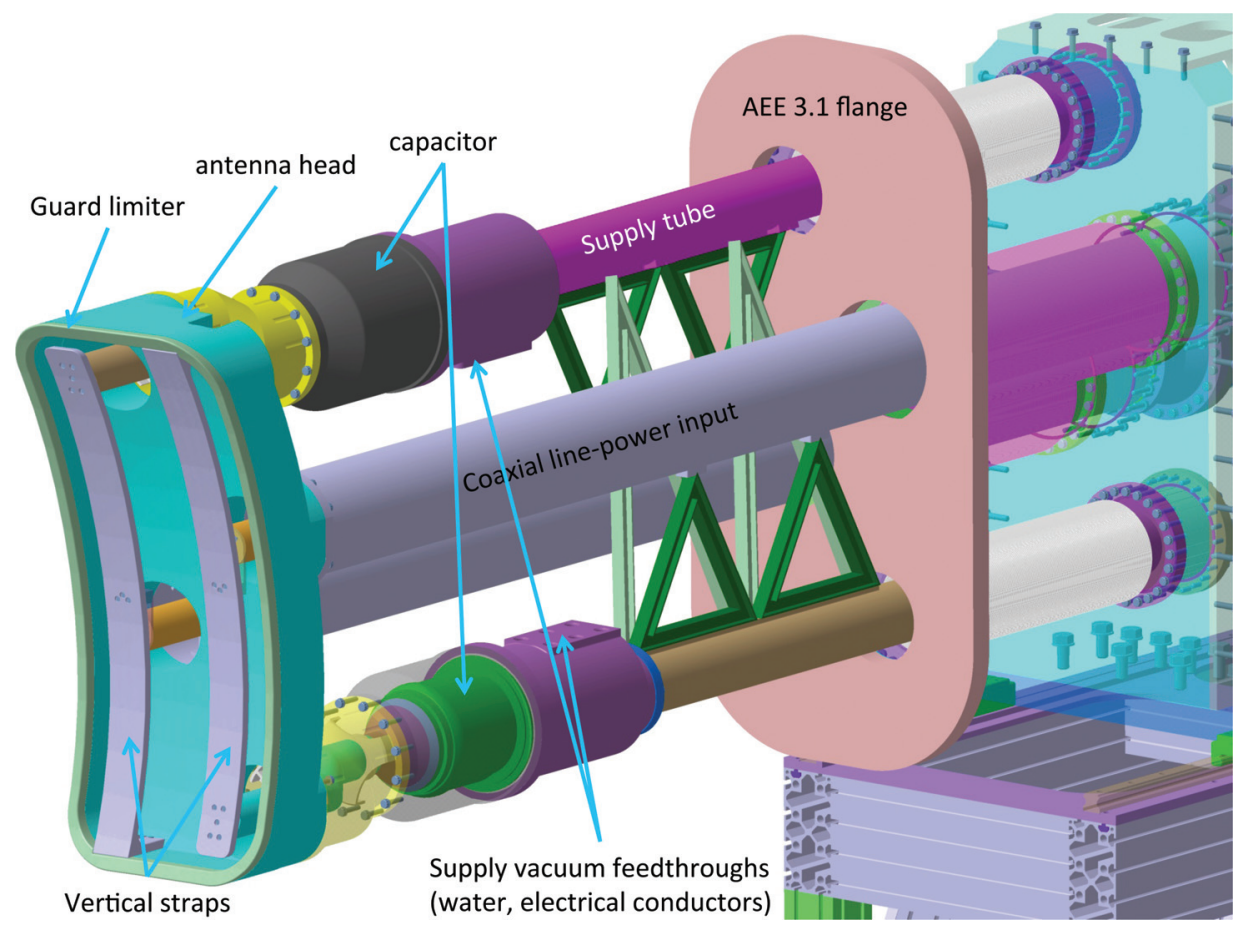

FIG. 21. Outline mechanical design of the antenna system inside port AEE3.1.

cause a variable loading of parts of the straps (Fig. 23) and therefore the ICRH coupling efficiency. To that end, a gas feed tube with several holes in poloidal direction along the sides of the antenna box will be implemented to maximise coupling independent of the plasma shape.

The position of the antenna box with respect to the LCMS for a given magnetic configuration of W7-X will also depend on the heat load from the plasma (thermal radiation, escaping fast particles, and micro wave stray radiation),

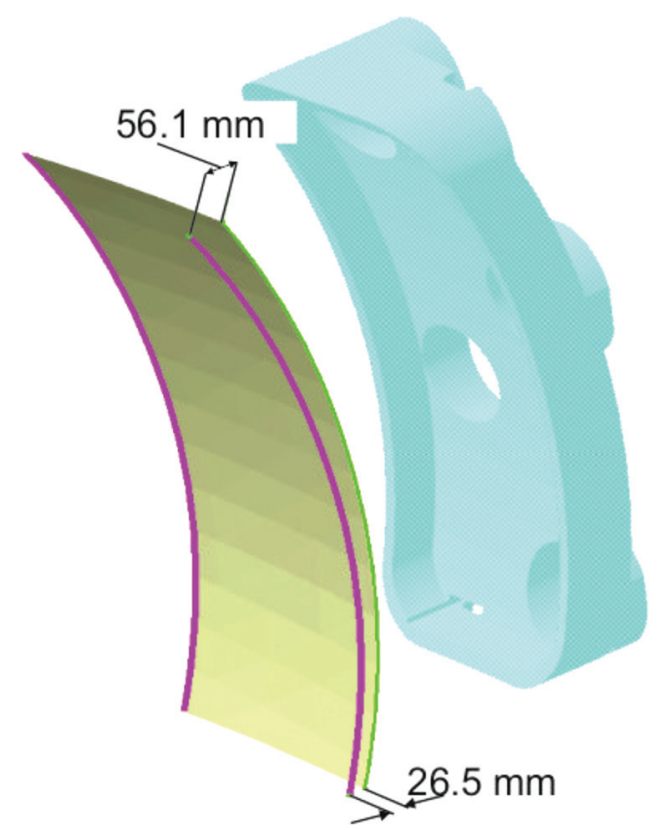

FIG. 22. Illustration of the poloidal and toroidal curvature of antenna head and straps. The gray surface represents the front face of the antenna box. The full line at the right is rotated toroidally along the vertical axis of W7-X. The numbers on the top and bottom of the strap indicate the deviations from a pure poloidal shape at the rear front side of the antenna head. which should be below $2 \mathrm{MW} / \mathrm{m}^{2}$ at the straps and edges of the antenna box, as discussed below.

The antenna is mounted on a movable truck, which allows a change of position with a velocity of maximum $2 \mathrm{~mm} / \mathrm{s}$ even during plasma operation. A mechanical decoupling from the outer vessel is achieved by edge welded bellows covering the RF vacuum transmission lines.

\section{Cooling conditions for long pulse plasma operation}

A challenging task in the antenna design is the integration of the cooling circuits. The resistive losses of the RF power in transmission lines and antenna box for durations of about $20 \mathrm{~s}$ must be removed. A total maximum power loss of $200 \mathrm{~kW}$ mostly deposited in the straps and antenna box was assumed for both circuits. Therefore, the straps and the antenna box must be actively cooled by two water circuits. Inside the transmission lines in vacuum the temperature rise is tolerable even for the most critical duty cycle of $20 \mathrm{~s}$ "on"
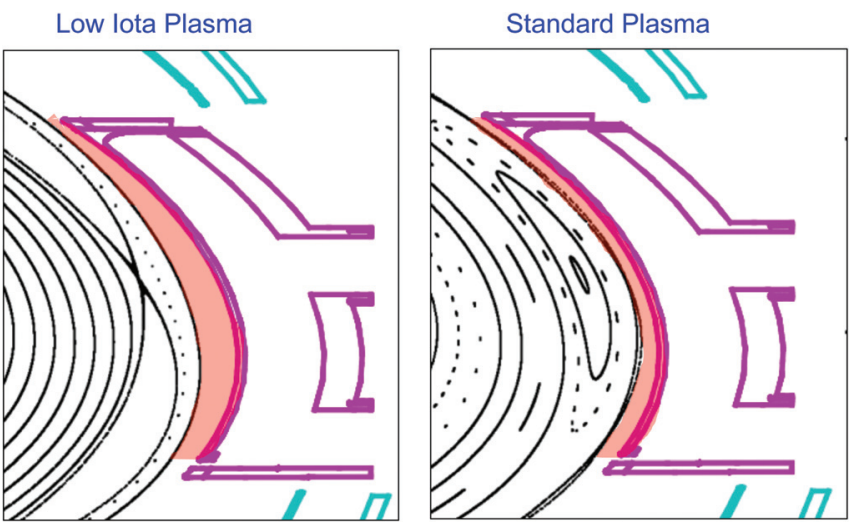

FIG. 23. Illustration of the variation in plasma-strap distance between the low iota and standard configuration. 


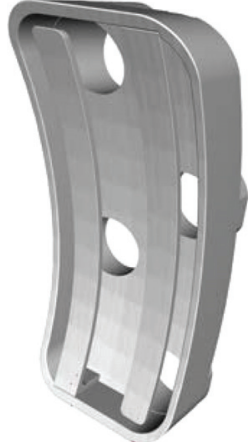

$275 \mathrm{~mm}$

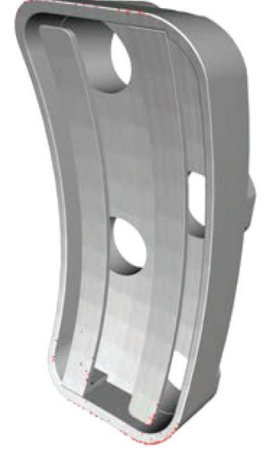

$280 \mathrm{~mm}$

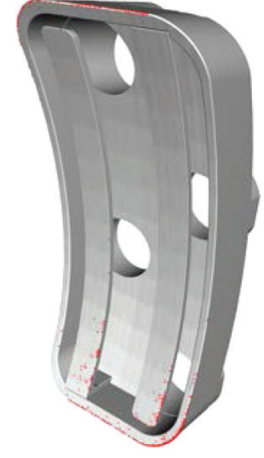

$285 \mathrm{~mm}$

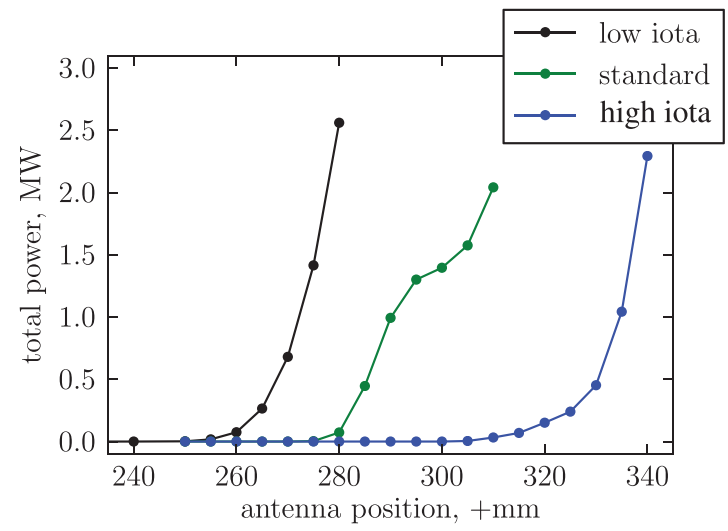

(b)

(a)

FIG. 24. (a) Plasma load on the edges on the antenna due to the ergodized magnetic field in the plasma edge. The antenna shape is aligned to the shape of the LCMS of the (standard) plasma configuration. When moving the antenna closer to the plasma, an additional load appears at the top and bottom of the antenna box, due to the presence of ergodized magnetic lines at the location of island structures. To avoid local hot spots an IR observation system, allowing feedback on the antenna radial position is under consideration. The positions indicated are relative to the position of the antenna when it is retracted in the port, as shown in the x-axis of Fig. 24(b). (b) Illustration of the rapid increase of the total heat load on the antenna (from ergodized field lines only) when approaching the LCMS for the low iota, high iota, and standard plasma configuration.

to $120 \mathrm{~s}$ "off" and they therefore need no active cooling. In addition, we need to take into account the power flux from the plasma to the antenna box. In parking position an average power of $14 \mathrm{~kW}\left(50 \mathrm{~kW} / \mathrm{m}^{2}\right)$ must be removed for the full plasma duration. This value can increase significantly at the carbon limiters of the antenna box if the antenna is moved towards the LCMS especially if magnetic islands would be present close to the antenna box. Modeling of the power flow towards the plasma facing surfaces of the antenna box will be performed and will determine the detailed 3D shape of the graphite limiter at the edges of the antenna box. ANSYS calculations will deliver surface temperatures of the critical components for a given water flow and will determine the acceptable positions of the antenna for all plasma configurations. Thermocouples in the limiter surfaces open the possibility of implementing a feedback system. A significant part of the ICRH power will also be dissipated in the capacitors, and therefore they will be connected to separate water cooling circuits.

A calculation of the heat load on the antenna from convective losses is shown in Fig. 24(a) for three different radial positions of the antenna with the plasma corresponding to the standard magnetic field configuration. As the antenna is moved in, we clearly see the appearance of extra loading on the lower and upper boundaries of the antenna. This is due to the presence of islands close to the antenna, causing an ergodization of the magnetic field in the edge. Fig. 24(b) shows the rapid increase of the total heat load when approaching the LCMS for the three configurations.

\section{Grounding of the antenna box}

The antenna box should be grounded to the wall of the port duct to avoid RF resonances excitation in the space between the port duct and the antenna plug-in behind the antenna box. ${ }^{16}$ The antenna structure must be encapsulated in a metal enclosure until the location of the short circuit.

\section{E. Safety system}

Operation of the antenna system requires the monitoring of all temperatures at the antenna head and flow control in the cooling water circuits. Input from the RF power measurement is necessary for the operation of the generators.

\section{ANTENNA DIAGNOSTIC SYSTEMS}

The diagnostics that will be integrated into the antenna head are:

- Power detector at the capacitors $\left(\mathrm{U}_{\mathrm{RF}}\right.$ and $\left.\mathrm{I}_{\mathrm{RF}}\right)$

- Thermocouples at the antenna guard limiter (type $\mathrm{K}$ for temperatures up to $1250{ }^{\circ} \mathrm{C}$ )

- IR diagnostic of the antenna box, especially of the guard limiter and straps, is desirable to allow feedback

- Control of power load by adjusting the distance to the LCFS

- Pt100 sensors at the antenna box and coaxial tubes (temperatures up to $200{ }^{\circ} \mathrm{C}$ )

- Probes in the guard limiters (plasma parameters)

- Pressure gauges for vacuum control (pressure control in the rear side antenna port)

- Probes for the RF voltage und current in the antenna box.

In addition, a dedicated gas injection system close to the antenna box for optimizing ICRH coupling under all circumstances will be implemented.

${ }^{1}$ J. Nuehrenberg, W. Lotz, P. Merkel, C. Nuehrenberg, U. Schwenn, E. Strumberger, and T. Hayashi, Proceedings of the Sixth International Toki Conference on Plasma Physics and Controlled Nuclear Fusion - Research for Advanced Concepts in Magnetic Fusion, Transactions of Fusion Technology Vol. 27 (American Nuclear Society, 1995), p. 71.

${ }^{2}$ R. Wolf and Wendelstein Team, Fusion Eng. Des. 83, 990 (2008).

${ }^{3}$ A. Messiaen, A. Krivska, F. Louche, J. Ongena, P. Dumortier, F. Durodie, D. Van Eester, and M. Vervier, "Coupling and matching study of the ICRF Antenna for W7-X," AIP Conf. Proc. 1580, 354 (2014).

${ }^{4}$ A. Messiaen, R. Koch, R. R. Weynants, P. Dumortier, F. Louche, R. Maggiora, and D. Milanesio, Nucl. Fusion 50, 025026 (2010).

${ }^{5}$ A. Messiaen and R. Weynants, Plasma Phys. Controlled Fusion 53, 085020 (2011). 
${ }^{6}$ D. Van Eester and R. Koch, Plasma Phys. Controlled Fusion 40, 1949 (1998).

${ }^{7}$ D. Van Eester and E. Lerche, Plasma Phys. Controlled Fusion 53, 092001 (2011).

${ }^{8}$ T. H. Stix, Waves in Plasmas (American Institute of Physics, New York, 1992).

${ }^{9}$ F. Durodié, M. Vrancken, R. Bamber, P. Dumortier, D. Hancock, D. Lockley, R. Maggiora, F. Louche, A. Messiaen, D. Milanesio, M. Nightingale, M. Shannon, P. Tigwell, M. Van Schoor, D. Wilson, K. Winkler, and CYCLE Team, in Proceedings of the 24th International Atomic Energy Agency (IAEA) Fusion Conference, San Diego, Paper No. ITR/P1-08.

${ }^{10}$ V. Lancellotti, D. Milanesio, R. Maggiora, G. Vecchi, and V. Kyrytsya, Nucl. Fusion 46, S476 (2006).
${ }^{11}$ CST Microwave Studio, User Manual Version 2009, September 2008, CST AG, Darmstadt, Germany, see www.cst.com.

${ }^{12}$ A. Messiaen, P. Dumortier, V. Kyrytsya, F. Louche, and M. Vervier, Fusion Eng. Des. 86, 855 (2011).

${ }^{13} \mathrm{~F}$. Durodié and M. Vervier, in Proceedings of the 17th Symposium on Fusion Technology, Roma, Italy, 14-18 September, 1992, p. 477.

${ }^{14}$ A. Messiaen, M. Vervier, P. Dumortier, D. Grine, P. U. Lamalle, F. Durodié, R. Koch, F. Louche, and R. Weynants, Nucl. Fusion 49, 055004 (2009).

${ }^{15}$ F. Durodié, Phys. Plasmas 21, 061512 (2014).

${ }^{16}$ P. Dumortier, V. Kyrytsya, F. Louche, A. Messiaen, M. Vervier, and F. Durodié, "ITER ICRH antenna grounding options," Fusion Eng. Des. 88, 922 (2013). 